\title{
Simulação Numérica de Escoamentos Multifásicos utilizando o Sistema FreeFlow-2D
}

\author{
Fernando Luiz Pio dos Santos
}

Orientador: Prof. Dr. Norberto Mangiavacchi

Dissertação apresentada ao Instituto de Ciências Matemáticas e de Computação da Universidade de São Paulo - ICMC/USP, como parte dos requisitos para a obtenção de título de Mestre em Ciências Matemática e Matemática Computacional.

USP - São Carlos

Junho de 2001 

"Para ser grande, sê inteiro: nada

Teu exagera ou exclui

Sê todo em cada coisa. Põe quanto és

No mínimo que fazes

Assim em cada lago a lua brilha

Brilha, porque alto vive."

(Fernando Pessoa-Ricardo Reis) 
Dedico este trabalho a minha mãe,

Anália. 


\section{Agradecimentos}

Primeiramente gostaria de agradecer ao meu orientador, prof. Norberto, pela grande dedicação e notavél paciência durante todo este tempo de mestrado. É admirável a forma com que me atendeu e atende a todos as outras pessoas que o solicitam. Portanto, ao prof. Norberto um especial agradecimento por eu ter conseguido realizar este trabalho.

Aos professores do grupo de Análise Numérica, sempre presentes no laborátorio LCAD colaborando com valiosas sugestões. Em especial ao prof. Castelo, ao prof. Murilo, ao prof. Poti e ao prof. Gustavo.

Aos professores da Unesp de S. J. Rio Preto onde me formei, pelo importante incentivo em dar continuidade em meus estudos em Matemática. Em especial ao Adalberto (meu ex-orientador de Iniciação Científica), à Angela, à Neuza e ao Nino.

À minha família, pelo grande apoio e incentivo em todos os momentos da minha vida. Pois sem eles, eu não poderia estar aqui realizando meu sonho. Em especial à minha querida mãe Anália, ao Felipinho, a Rose, aos meus tios e tias e às minhas queridas primas Ana, Gisele, Samantha, Letícia e Maricí.

Aos amigos do LCAD que também foram muito importantes pra mim, pelas ajudas e sugestões e principalmente pela amizade que se formou. Em especial à Juliana (JMaria), à Luciane (Lu Grossi), à Luciana (Lu Paiva), ao Valdemir, pelas importantes dicas no momento final do projeto, ao Marcelo, ao Fabrício, ao Ricardo e ao Alex.

À Monica, pessoa a qual eu tenho grande admiração e carinho, pelo respeito, pela grande ajuda nas tarefas do dia-a-dia, e por estar presente e ter paciência em me escutar nos momentos difícieis.

A todos os meus amigos e amigas da USP, em especial ao Thiago (Gabiru), Silvio (Silvinho), ao Juliano (Zuzu), ao Wellington (Barra), ao Ricardo, ao Marcio, à Rubia, à Selma, à Lilian, à Sandra, à Cilene e à Valeria, pelos bons momentos de descontração.

Agradeço todos aqueles que diretamente ou indiretamente colaboram para a realização deste trabalho.

À agência CNPq, pelo suporte financeiro para o desenvolvimento deste projeto. 


\section{Resumo}

Neste trabalho descreve-se um método para expandir a aplicabilidade do sistema FreeFlow-2D para problemas de escoamentos de fluidos multifásicos. Este método permite a simulação de escoamento de fluido multifásico, incompressível e com superfície livre. Um número arbitrário de fases com propriedades diferentes pode ser utilizado. Tensões superficial e interfacial são também consideradas.

A técnica numérica utilizada baseia-se no GENSMAC (Generalized-Simplified-Markerand-Cell) [23] e considera-se propriedades variáveis de acordo com a posição da interface durante o escoamento. O campo de velocidade é computado utilizando-se as equações de Navier-Stokes discretizadas por esquema de diferença finitas numa malha deslocada.

O método foi implementado em três módulos: Modelador, Simulador e Visualizador. A validação foi efetuada comparando-se os resultados numéricos com resultados analíticos e experimentais. O método mostrou-se robusto e computacionalmente eficiente para os problemas considerados. 


\begin{abstract}
This work describes a method to expand the applicability of the system FreeFlow-2D in multi-phase flows problems. This method allows the simulation of incompressible free surface multi-phase flows. An arbitrary number of phases having different properties can be used. Surface and interface tension effects are also considered.

The numerical technique is based on the GENSMAC (Generalized-Simplified-Markerand-Cell) [23] and it considers the properties varying according to the position of the interfaces in the flow. The velocity field is computed using the Navier-Stokes equations discretized by finite-difference on stagered grid.

The method was implemented in three modules: the modeling module, the simulation module, and the visualization module. The validation was effected by comparing numerical results with analytical and experimental results. The method shown to be robust and computationally efficient in the problems considered.
\end{abstract}




\section{Sumário}

1 Introdução 1

2 Equações de Movimento 5

2.1 Introdução . . . . . . . . . . . . . . . . 5 5

2.2 Equações de Navier-Stokes . . . . . . . . . . . . . . . . . 5

2.3 Equações de Navier-Stokes para Escoamento Multifásico Incompressível 8

2.4 Forma Bidimensional para as Equações de Navier-Stokes . . . . . . . . . 11

2.5 Condições de Contorno . . . . . . . . . . . . . . . . . . 12

2.6 Forma Adimensional . . . . . . . . . . . . . . . . . . 15

2.6.1 Adimensionalização das Equações de momento e condição de incompressibilidade .................... 16

2.6.2 Adimensionalização das Equações de Condições de Contorno na Superfície Livre . . . . . . . . . . . . . . 18

2.7 Cálculo da Curvatura . . . . . . . . . . . . . . . . . . 19

3 Cálculo da Velocidade e Pressão 23

3.1 Introdução . . . . . . . . . . . . . . . . . . 23

3.2 Procedimento do Cálculo da Velocidade e Pressão . . . . . . . . . . . . 23

4 Discretizações $\quad 27$

4.1 Introdução . . . . . . . . . . . . . . . . . 27

4.2 Definição das Células . . . . . . . . . . . . . . . . . . 28

4.3 Discretizações das Equações de Momento . . . . . . . . . . . . . . 29

4.4 Discretização da Equação Elíptica para $\psi$. . . . . . . . . . . . 38

4.4 .1 Solução da Equação Elíptica para $\psi$. . . . . . . . . . . . . 39 
4.5 Procedimento de Aproximação da Interface e de Distribuição da Tensão Interfacial . . . . . . . . . . . . . . . . . 40

4.6 Condições de Contorno na Superfície Livre . . . . . . . . . . . . 44

4.7 Controle do Passo no Tempo . . . . . . . . . . . . . . . . 47

5 Ambiente FreeFlow-2D de Simulação Numérica 49

5.1 Introdução . . . . . . . . . . . . . . . . . . . . . 49

5.2 O Ambiente de Simulação FreeFlow-2D . . . . . . . . . . . . . 49

5.3 Módulos do Sistema FreeFlow-2D para Escoamento Multifásico . . . . . . 50

5.3 .1 O Modelador Multifásico . . . . . . . . . . . . 50

5.3 .2 Estratégia de Inclusão de Fases . . . . . . . . . . . 53

5.3 .3 O Simulador Multifásico . . . . . . . . . . . 54

5.3 .4 O Visualizador Multifásico . . . . . . . . . 56

5.3.5 Estrutura de Dados e Estratégias de Reconhecimento de Fases . . 57

$\begin{array}{lll}6 & \text { Resultados Numéricos } & 61\end{array}$

6.1 Introdução . . . . . . . . . . . . . . . . 61

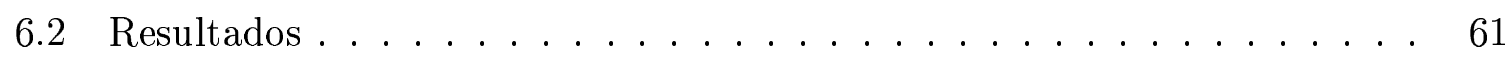

6.2.1 Campo de Pressão com uma Gota Circular sem Campo de Gravidade 61

6.2.2 Oscilação de uma Bolha Elíptica . . . . . . . . . . . . 64

6.2.3 Ascensão de uma Bolha Imersa em uma Fase Contínua . . . . . 67

6.2.4 Efeitos da Tensão Interfacial . . . . . . . . . . . . . . . . 75

6.2.5 Simulação Numérica de Escoamentos com Três ou mais Fases . . . 76

6.2.6 Problemas com Injeção de Fluidos . . . . . . . . . . . . 81

7 Conclusões $\quad 91$

7.1 Trabalhos Futuros . . . . . . . . . . . . . . 92

$\begin{array}{ll}\text { Referências Bibliográficas } & 93\end{array}$ 


\section{Lista de Figuras}

2.1 Deslocamento de um elemento de fluido com o escoamento . . . . . . 5

2.2 Posição dos vetores normal e tangencial numa superfície livre ou interface 13

2.3 Aproximação de uma superfície pelo método dos mínimos quadrados . . . 20

4.1 Configuração de uma Célula . . . . . . . . . . . . . . 27

4.2 Indentificação das células interfaces entre as fases $i$ e $j \quad \ldots . \ldots 29$

4.3 Pontos de discretização e faces envolvidas para o esquema de aproximação de termos convectivos . . . . . . . . . . . . 35

4.4 Pontos de aproximação da velocidade $u_{i+1, j} \operatorname{com} \bar{u}_{i+1, j} \geq 0 \ldots \ldots$. . . . 36

4.5 Pontos de aproximação da velocidade $u_{i+1, j} \operatorname{com} \bar{u}_{i+1, j}<0 \ldots \ldots$. . . 37

4.6 Pontos de aproximação da velocidade $u_{i, j} \operatorname{com} \bar{u}_{i, j} \geq 0$. . . . . . . 37

4.7 Pontos de aproximação da velocidade $u_{i+1, j} \operatorname{com} \bar{u}_{i, j}<0 \ldots \ldots \ldots$. . . 37

4.8 Célula interface com lados esquerdo e direito adjacentes à células $\mathrm{F}$ de cada fase . . . . . . . . . . . . . . . . . 42

4.9 Célula interface com lados adjacentes não opostos à células F de cada fase 43

4.10 Célula interface com três faces adjacentes à células F . . . . . . . . 43

4.11 Célula interface com três faces adjacentes à células F . . . . . . . . . 44

4.12 Célula $\mathrm{S}$ com o lado direito em contato com uma célula E . . . . . . 45

4.13 Célula $\mathrm{S}$ com dois lados em contato com células E . . . . . . . . . 46

5.1 Entrada de dados e especificação do número de fases para criação de um modelo multifásico . . . . . . . . . . . . . . 51

5.2 Entrada do número de fase para os fluidos . . . . . . . . . 51

5.3 Entrada das propriedades de cada fase . . . . . . . . . . . 52

5.4 Definição de fase no injetor . . . . . . . . . . . . . . 52

5.5 Etapa intermediária para a inclusao de fases . . . . . . . . . . 53 
5.6 Configuração das células de cada fase separadamente . . . . . . . . . 54

5.7 Configuração global das células do modelo bifásico . . . . . . . . . . . . 54

5.8 Estrutura de comunicação entre os módulos . . . . . . . . . . . 57

5.9 Fatia (S) e Face (F) obtidas com um corte num sólido . . . . . . . . 58

5.10 Estrutura de dados do FreeFlow 2D . . . . . . . . . . . 58

6.1 Pressão Capilar da gota. . . . . . . . . . . . . . . . 62

6.2 Pressão capilar em função do raio da bolha. Comparação do valor numérico

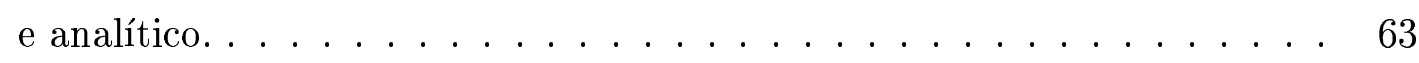

6.3 Oscilação de um bolha elíptica nos tempos: $\mathrm{t}=0.0 ; \mathrm{t}=0.0013 ; \mathrm{t}=0.0026 .64$

6.4 Decaimento exponencial da amplitude de oscilação da bolha. . . . . . . . 65

6.5 Velocidade ascendente da bolha em $\mathrm{t}=0.0001 . \ldots \ldots 6$

6.6 Velocidade descendente da bolha em $\mathrm{t}=0.0023 \ldots \ldots \ldots 6$

6.7 Ascensão da bolha em uma fase contínua. . . . . . . . . . . 68

6.8 Velocidade de ascensão da bolha. . . . . . . . . . . . . . 69

6.9 Velocidades no tempo $t=0.237 \ldots \ldots \ldots \ldots$

6.10 Pressão no tempo $t=0.237 \ldots \ldots \ldots \ldots \ldots$

6.11 Bolha circular em $\mathrm{t}=0.0 \ldots \ldots \ldots \ldots \ldots \ldots \ldots$

6.12 Ascensão da bolha em uma fase contínua . . . . . . . . . . . 72

6.13 Velocidade e variação da altura da bolha $\left(h_{\max }-h_{\operatorname{mim}}\right) . \ldots . . . . .73$

6.14 Pressão do fluido externo e da bolha no tempo $t=0.1 \ldots$. . . . . 73

6.15 Velocidades $x$ e $y$ no tempo $\mathrm{t}=0.134 \ldots \ldots \ldots \ldots \ldots$

6.16 Pressão no tempo $t=0.134 \ldots \ldots \ldots \ldots \ldots$. . . . . . . . . . . . .

6.17 Efeitos da tensão superficial na bolha; malha 36 x 64 células computacionais 75

6.18 Comportamento da velocidade e achatamento das bolhas . . . . . . 76

6.19 Evolução de duas bolhas de propriedades distintas numa fase contínua. $\quad 77$

6.20 Velocidades $x$ e $y$ em $\mathrm{t}=0.257 \ldots \ldots \ldots \ldots \ldots$

6.21 Pressão no tempo $t=0.257 \ldots \ldots \ldots \ldots \ldots \ldots$

6.22 Estado inicial das bolhas no tempo $t=0.0 \ldots \ldots \ldots . \ldots 79$

6.23 Evolução de cinco bolhas de diferentes propriedades . . . . . . . . . . 80

6.24 Simulação com injetor no FreeFlow-2D multifásico e no FreeFlow-2D no tempo $t=0.0 \ldots \ldots \ldots \ldots \ldots \ldots$ 
6.25 Simulação com injetor no FreeFlow-2D multifásico e no FreeFlow-2D nos tempos $\mathrm{t}=0.07, \mathrm{t}=0.25 \mathrm{e} \mathrm{t}=0.75 \ldots \ldots . \ldots 82$

6.26 Pressões em $t=0.17 \ldots \ldots \ldots \ldots$. . . . . . . . . 83

6.27 Velocidades na direção $x$ em $\mathrm{t}=0.17 \ldots \ldots \ldots \ldots$. . . . . . 84

6.28 Velocidades na direção $y$ em $\mathrm{t}=0.17 \ldots \ldots \ldots \ldots$. . . . . 84

6.29 Injeção de fluido no tempo $t=0.0 \ldots \ldots \ldots \ldots$

6.30 Injeção de fluido sobre a superfície livre de outro fluido. . . . . . . . 86

6.31 Velocidades no tempo $t=0.6 \ldots \ldots \ldots$. . . . . . . 87

6.32 Pressão no tempo $t=0.6 \ldots \ldots \ldots \ldots$. . . . . . . . 87

6.33 Injeção de fluido no tempo $t=0.0 \ldots \ldots \ldots$

6.34 Injecao de fluido pelo fundo do container. . . . . . . . . . . . 89

6.35 Velocidades na direção $x$ e $y$ no tempo $t=0.3075 \ldots \ldots . \ldots . . . .90$

6.36 Pressão no tempo $t=0.3075 \ldots \ldots \ldots \ldots$. . . . . . . . 90 


\section{Capítulo 1}

\section{Introdução}

Este trabalho tem por objetivo desenvolver módulos para modelar, simular e visualizar escoamentos multifásicos com superfícies livres e interface entre dois ou mais fluidos, incluindo efeitos de tensão superficial e pressão capilar.

Simulação numérica de escoamentos de fluidos é uma área da Mecânica dos Fluidos Computacional (MFC) e tem diversas aplicações industriais importantes, tais como refino e distribuição de petróleo e gás natural, com um papel importante no segmento de transporte, produção, desenvolvimento da engenharia de processos e unidades operacionais.

A área de MFC que trata de simulação de escoamentos de fluidos tem obtido sucessos graças ao estudo de novas técnicas numéricas, juntamente com o avanço significativo dos atuais computadores, permitindo assim que os resultados de tais simulações sejam bem mais precisos e efetuados em tempo relativamente menor. Isto diminui os custos e viabiliza a pesquisa nesta área.

O ambiente de simulação que vem sendo desenvolvido pelo grupo de Análise Numérica do Instituto de Computação e Matematica Computacional (ICMC/USP) denominado FreeFlow tem por objetivo simular escoamentos com superfícies livres em duas e três dimensões. Este ambiente está baseado no método GENSMAC [23], e este por sua vez é um aperfeiçoamento do método MAC [26] e SMAC [2].

Simulação numérica é, em geral, mais conveniente para estudar estes tipos de escoamentos, devido vantagens tais como a facilidade de se armazenar informações e a facilidade de se esclarecer vários processos físicos. Porém a computação numérica de 
escoamentos com interface é mais trabalhosa, por exemplo, nos casos em que a interface separa fluidos de diferentes densidades, tais como água e óleo. Existem basicamente duas técnicas usadas em simulações de escoamentos com interface: Captura (Capturing) e Acompanhamento (Tracking). Em Interface Capturing, a interface é tratada como uma região com variação acentuada, mas com algumas propriedades mantendo-se contínuas. Experimentos numéricos têm mostrado que esta metodologia não requer detalhes adicionais no algoritmo para modelar trocas topologicas na interface. A desvantagem é que há uma difusão da interface sobre várias células, resultando numa perda de precisão. Um exemplo desse método é o denominado conjunto de nível de uma função (Level-Set methods).

Aproximação Level-Set foi introduzida por Osher e Sethian [22]. Neste método, a interface é representada por um conjunto de nível de uma função suave $\phi$. Esta representação conduz a fórmulas convenientes para o cálculo da normal e curvatura da interface, e não utiliza procedimentos especiais para modelar trocas topológicas numa frente. Simplesmente atualiza-se o valor da função $\phi$ em cada passo no tempo e a localização da frente, no novo tempo, é simplesmente o contorno zero de $\phi$. Um outro método que utiliza esta metodologia é o denominado Volume-of-Fluid [16]. Neste método rastreia-se o volume ocupado por cada fase em cada célula a cada passo no tempo, e estes volumes são usados para reconstruir uma aproximação da frente ou interface.

Em Interface Tracking, a interface é tratada explicitamente como uma forma descontínua movendo-se sobre a malha. Este método oferece uma precisão melhor do que o anterior, mas há um custo maior de complexidade algorítmica. Utilizando esta metodologia de representação da interface pode-se destacar os métodos denominados Front-Tracking, Volume-Tracking e Boundary Integral.

Segundo [25], Volume-Tracking é um método razoavelmente preciso e relativamente fácil de ser implementado, e utiliza-se de partículas marcadoras para a reconstrução da interface. Além disso, segundo [25], pode-se obter a mesma precisão com um custo consideralvemente menor, usando o método do tipo Front-Tracking, onde somente a interface é descrita com a adição de partículas marcadoras. É esta precisão que permite que se resolvam características de finas escalas da frente numa malha relativamente grossa. Neste método, partículas marcadoras (ou elemementos computacionais) são introduzidos explicitamente para marcar o curso da frente. A vantagem desse método é permitir que 
se planeje arbitrariamente aproximações de alta ordem para a frente que se modifica suavemente. Um problema resulta da interação de uma frente com outra (ou outra parte de uma mesma frente). Geralmente o procedimento computacional não reconhece mais do que uma frente em cada célula da malha estacionária. Por isto, interfaces duplas têm de ser unidas ou eliminadas.

O método MAC (Marker-and-Cell) [26] é um esquema de diferenças finitas para investigar a solução numérica de escoamentos de fluido viscoso e incompressível com superfície livre. Sua principal característica é o uso de partículas marcadoras (ou virtuais) cujas trajetórias seguem o movimento do fluido pelos elementos. As coordenadas iniciais de um conjunto de partículas marcadoras são assumidas como conhecidas, mas não participam dos cálculos, servem apenas para definir uma configuração do fluido. Se uma célula contém uma partícula, esta é então considerada conter fluido. Dificuldades apresentadas nos cálculos da velocidade e pressão, devido ao precesso iterativo, motivaram Amsdem e Harlow a desenvolver o SMAC (Simplified MAC) [2] que contorna o problema da iteratividade dos cálculos dividindo-o em duas partes: uma para o campo de velocidade e outra para o campo de pressão, de forma que não exista processo iterativo envolvendo velocidade e pressão. Em 1997, Vicenzo Armenio desenvolveu o método SIMAC (SemiImplicit MAC) [3], apresentado também como método MAC modificado, para tratar de problemas de superfície livre com alto número de Reynolds, e resolve as equações de Navier-Stokes numa malha não-uniforme por meio de esquemas de diferenças finitas. Tal como no MAC, a superfície livre é tratada por partículas marcadoras que dividem o domínio de integração em células cheias e vazias. O tratamento do termo convectivo é feito por um esquema explícito upwind de segunda ordem no espaço denominado HLPA (Hybrid Linear Parabolic Approximation) e técnicas Adams-Basforth no tempo. O termo Difusivo é tratado por uma técnica semi-implícita de fatoração aproximada. Para a pressão, é utilizada uma técnica multigrid baseada na estratégia de correção aditiva que acelera a convergência na resolução da equação de Poisson, diminuindo o tempo de processamento para os cálculos do campo de velocidade. Vários outros métodos são exemplos típicos de MAC modificado, tais como: SUMMAC, SOLA-VOF e TUMMAC, os quais têm em comum com o SIMAC a subdivisão do domínio computacional em células cheia, vazia e superfície livre, e a solucão da equação de Poisson para Pressão e atualização explicita do campo de velocidade. 
Tomé e Mckee [23], motivados pelo alto potencial de aplicabilidade do SMAC em problemas de injeção de alta velocidade de materiais dentro de moldes complexos, desenvolveram o método GENSMAC (Generalized-Simplified-Marker-and-Cell) para simulação de escoamento incompressível bidimensional de fluidos com superfície livre em domínios complexos, quando a condição de sem-escorregamento (no-slip) e escorregamento livre (free-slip) é imposta em fronteiras curvas. O GENSMAC (e também o MAC e SMAC) resolve as equações de Navier-Stokes usando uma malha diferenciada. O método foi escrito em FORTRAN com características de FORTRAN 90, possui uma rotina para definição automática de passo no tempo, a qual permite que a restrição de estabilidade seja otimizada, utiliza o método de Gradientes Conjugados para resolver uma equação de Poisson para o campo de velocidade corrente e contém uma aproximação precisa para a condição de pressão na superfície livre.

Castelo A. et al. descreveram um método incorporando a tensão superficial para o código GENSMAC2D [5]. A incorporação da tensão superficial foi realizada em duas escalas: na escala de uma célula, onde os efeitos da tensão superficial são incorporados dentro das condições de fronteira da superfície livre através dos cálculos da pressão capilar, e na escala de uma sub-célula, onde pequenas perturbações de ondas são "filtradas" usando-se um estêncil de quatro pontos, no qual a massa é conservada. Para estimar a pressão capilar, usa-se o método dos mínimos quadrados para determinar o raio do círculo que mais aproxima a superfície livre numa célula, usando-se as coordenadas das partículas marcadoras na célula e em sua vizinhança.

O ambiente de simulação de escoamentos de fluidos em duas e três dimensões com superfície livre denominado FreeFlow, baseado no método GENSMAC, vem sendo desenvolvido no ICMC/USP e faz parte do projeto SNENS-II (Solução Numérica das Equações de Navier-Stokes). Um dos objetivos deste projeto é expandir a aplicabilidade de simulação para novos tipos de escoamento bidimensional e tridimensional. Neste sentido, este projeto de mestrado teve o propósito de desenvolver módulos para o sistema FreeFlow$2 \mathrm{D}$, que permitam simular escoamentos multifásicos com superfícies livres e interface entre dois ou mais fluidos, incluindo os efeitos da tensão superficial e interfacial. 


\section{Capítulo 2}

\section{Equações de Movimento}

\subsection{Introdução}

Este capítulo descreve as equações de movimento (Equações de Navier-Stokes), para escoamentos multifásicos. As condições de contorno apropriadas para este tipo de escoamento, o procedimento de adimensionalização e o cálculo da curvatura.

\subsection{Equações de Navier-Stokes}

Considere um elemento de fluido se deslocando com o escoamento de um ponto (1) para um ponto (2) no plano cartesiano, em um intervalo de tempo $\delta t$, conforme ilustra a figura (2.1).

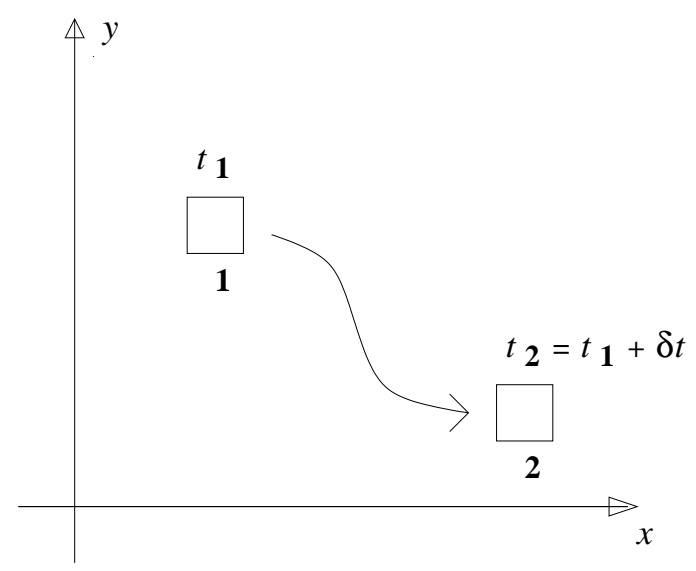

Figura 2.1: Deslocamento de um elemento de fluido com o escoamento

Em escoamentos transientes, as propriedades (macroscópicas) do fluido dependem 
das coordenadas espaciais e também temporal, como por exemplo, a velocidade $u=$ $u(\mathbf{x}, t)$ e $v=v(\mathbf{x}, t)$, a densidade $\rho=\rho(\mathbf{x}, t)$ e viscosidade $\mu=\mu(\mathbf{x}, t)$. Dessa forma, as coordenadas espaciais e temporal do elemento de fluido no ponto (1) são $\mathbf{x}_{1}=\left(x_{1}, y_{1}\right)$ e $t_{1}$, respectivamente. No ponto (2), as coordenadas são $\mathbf{x}_{2}=\left(x_{2}, y_{2}\right)$ e $t_{2}=t_{1}+\delta t$.

Assim, se uma propriedade $\phi$ está definida na posição (1) e também na posição (2), então $\phi_{1}=\phi_{1}\left(\mathbf{x}_{1}, t_{1}\right)$ e $\phi_{2}=\phi_{2}\left(\mathbf{x}_{2}, t_{2}\right)$. Para determinar como essa grandeza varia em função das coordenadas espaciais e temporal do elemento de fluido, entre estes dois pontos, basta expandir $\phi_{2}$ em série de Taylor ao redor do ponto $\phi_{1}$ e fazer $t_{2} \rightarrow t_{1}$ [8]. Procedendo dessa forma, obtém-se a derivada material (ou substantiva) de $\phi$

$$
\frac{D \phi}{D t}=\frac{\partial \phi}{\partial t}+u \frac{\partial \phi}{\partial x}+v \frac{\partial \phi}{\partial y}
$$

onde $u=\lim _{t_{2} \rightarrow t_{1}} \frac{x_{2}-x_{1}}{t_{2}-t_{1}}$ e $v=\lim _{t_{2} \rightarrow t_{1}} \frac{y_{2}-y_{1}}{t_{2}-t_{1}}$ são os valores instantâneos das componentes da velocidade no ponto 1 .

Introduzindo o operador $\nabla$, em coordenadas cartesianas bidimensionais, dado por

$$
\nabla=\frac{\partial}{\partial x} \mathbf{i}+\frac{\partial}{\partial y} \mathbf{j}
$$

em (2.1), obtém-se

$$
\frac{D \phi}{D t}=\frac{\partial \phi}{\partial t}+(\mathbf{u} \cdot \nabla) \phi
$$

onde $\mathbf{u}$ é o vetor campo de velocidade.

A conservação de massa é expressa pela equação da continuidade. Na ausência de fontes ou sorvedouros de massa, o equilíbrio é obtido considerando-se que a variação temporal da quantidade de massa no elemento é igual á vazão líquida de massa através das fronteiras do elemento, ou seja,

$$
\frac{\partial \rho}{\partial t}+\mathbf{u} \cdot \nabla \rho+(\rho \nabla) \cdot \mathbf{u}=0
$$

ou ainda, observando a equação (2.3), segue que

$$
\frac{D \rho}{D t}+(\rho \nabla) \cdot \mathbf{u}=0
$$


onde $\rho$ é a densidade do fluido e $\mathbf{u}$ é o vetor velocidade.

A equação (2.5) escrita usando o operador $\nabla$ independe do sistema de coordenadas. Assim, para se obter uma expressão em outro sistema de coordenadas, basta expressar o operador no sistema que se quer utilizar.

Se for considerado que a densidade de uma partícula material não se altera no tempo, tem-se

$$
\frac{D \rho}{D t}=0
$$

Logo, substituindo em (2.5), obtemos

$$
\rho \nabla \cdot \mathbf{u}=0
$$

Como $\rho \neq 0$, segue que

$$
\nabla \cdot \mathbf{u}=0
$$

onde $\mathbf{u}=(u, v)$ é o vetor velocidade e $\nabla$ é o operador dado por (2.2).

A equação (2.8) é conhecida como condição de incompressibilidade do fluido e esta condição será mantida em todo domínio, mesmo com o salto de algumas propriedades na interface.

A equação geral de conservação de momento é obtida aplicando-se a segunda lei de Newton, a qual afirma que a taxa de variação temporal de momento de uma partícula de fluido é igual á resultante das forças que agem sobre esta partícula. Assim, a equação geral, na forma vetorial, que rege a conservação de momento é

$$
\rho \frac{D \mathbf{u}}{D t}=\nabla \cdot \mathbf{S}+\rho \mathbf{g}+\mathbf{f}
$$

onde

$$
\mathbf{S}=-p \mathbf{I}+\tau
$$

é o tensor de tensões causadas pela pressão $p$ no fluido e tensões viscosas $\tau$ normais e de cisalhamento no escoamento. I é o tensor identidade e o produto $\rho \mathbf{g}$ representa a força de 
campo gravidade, sendo $\mathbf{g}$ o vetor de aceleração gravitacional. A força $\mathbf{f}$ também é uma força de campo e suas características serão descritas em uma seção posterior, quando estaremos restringindo as equações de momento para escoamentos multifásicos.

Para escoamentos newtonianos, o tensor de tensões $\tau$

$$
\tau=\left(\begin{array}{cc}
\tau_{x x} & \tau_{x y} \\
\tau_{y x} & \tau_{y y}
\end{array}\right)
$$

onde $\tau_{i j}$ é a tensão agindo na direção $i$ sobre a superfície normal à direção $j$ é definido como

$$
\tau=\mu\left[(\nabla u)+(\nabla u)^{T}\right]+\lambda(\nabla \cdot u) \mathbf{I},
$$

onde $\mu$ é o coeficiente de viscosidade do fluido e $\lambda=-\frac{2}{3} \mu$ é o segundo coeficiente de viscosidade (Hipótese de Stokes).

Assim, a equação de conservação de momento não conservativa na forma vetorial é dada por

$$
\rho \frac{D u}{D t}=-\nabla p+\mu \nabla^{2} \mathbf{u}+(\nabla \mu) \cdot\left[(\nabla u)+(\nabla u)^{T}\right]+\nabla[\lambda(\nabla \cdot u)]+\rho \mathbf{g}+\mathbf{f} .
$$

Utilizando-se a condição de incompressibilidade (2.8), obtém-se

$$
\rho \frac{D u}{D t}=-\nabla p+\mu \nabla^{2} \mathbf{u}+(\nabla \mu) \cdot\left[(\nabla u)+(\nabla u)^{T}\right]+\rho \mathbf{g}+\mathbf{f} .
$$

A equação (2.8), juntamente com a (2.13), são as equações de Navier-Stokes na forma não-conservativa, para escoamentos newtonianos bidimensionais.

\subsection{Equações de Navier-Stokes para Escoamento Mul- tifásico Incompressível}

Na simulação de escoamentos multifásicos bidimensionais, onde se têm dois ou mais fluidos, consideram-se, neste caso, fluidos viscosos, incompressíveis, e também os efeitos de tensão superficial e interfacial. 
Cada fluido envolvido na simulação determina uma fase. Assim, para a simulação deste tipo de escoamento considera-se todas as fases como um contínuo, e propriedades que mudam de acordo com a posição das partículas marcadoras da interface em cada ponto do escoamento como um todo.

Uma outra abordagem é considerar o escoamento em cada uma das fases como sendo um escoamento separado, com propriedades e composição constantes e determinar condição de acoplamento entre os diversos domínios de cada fase. Pode-se ainda considerar uma abordagem híbrida, onde no interior de cada fase são usadas as equações para propriedades constantes, e o acoplamento entre os domínios é obtido utilizando-se uma formulação de propriedades variáveis apenas para as células da interface.

Vale destacar que não era o propósito deste trabalho estudar a eficiência e aplicabilidade de metodologias que tratam de escoamento com a presença de interface. Contudo, justifica-se a escolha da primeira abordagem pela facilidade de tratamento e implementação da interface, devido a estrutura de dados utilizada no sistema FreeFlow-2D. A abordagem escolhida para implementação mostrou-se suficiente e robusta para o caso de escoamentos multifásicos bidimensionais, de forma que aliada à versatilidade da estrutura de dados utilizada no sistema, esta abordagem poderá ser também utilizada para a extensão até o caso de escoamento mulitifásico em três dimensões.

A equação de momento (2.13) está na forma não-conservativa. Para transformá-la na forma conservativa, considere-se a derivada material da grandeza $\phi$, dada por

$$
\frac{D \phi}{D t}=\frac{\partial \phi}{\partial t}+(\mathbf{u} \cdot \nabla) \phi
$$

e a identidade

$$
\nabla \cdot(\phi \mathbf{u})=\phi(\nabla \cdot \mathbf{u})+(\mathbf{u} \cdot \nabla) \phi
$$

Aplicando a condição de incompressibilidade (2.8), tem-se

$$
\nabla \cdot(\phi \mathbf{u})=(\mathbf{u} \cdot \nabla) \phi
$$

e portanto, a derivada material de $\phi$ na forma conservativa fica

$$
\frac{D \phi}{D t}=\frac{\partial \phi}{\partial t}+\nabla \cdot(\phi \mathbf{u})
$$


Esta forma é, portanto, restrita a problemas em que é válida a condição de incompressibilidade do fluido. Note que

$$
\begin{gathered}
\frac{D(\rho \mathbf{u})}{D t}=\frac{\partial(\rho \mathbf{u})}{\partial t}+(\mathbf{u} \cdot \nabla)(\rho \mathbf{u})= \\
=\mathbf{u} \frac{\partial \rho}{\partial t}+\rho \frac{\partial(\mathbf{u})}{\partial t}+\rho(\mathbf{u} \cdot \nabla) \mathbf{u}+\mathbf{u}(\mathbf{u} \cdot \nabla) \rho= \\
=\mathbf{u} \frac{D \rho}{D t}+\rho \frac{D \mathbf{u}}{D t}
\end{gathered}
$$

e novamente usando o fato de que $\frac{D \rho}{D t}=0$, tem-se

$$
\frac{D(\rho \mathbf{u})}{D t}=\rho \frac{D \mathbf{u}}{D t} .
$$

Logo, obtém-se a seguinte equação de momento na forma conservativa,

$$
\frac{D \rho u}{D t}=-\nabla p+\mu \nabla^{2} \mathbf{u}+(\nabla \mu) \cdot\left[(\nabla u)+(\nabla u)^{T}\right]+\rho \mathbf{g}+\mathbf{f}
$$

$\mathrm{ou}$

$$
\frac{\partial \rho \mathbf{u}}{\partial t}+\nabla \cdot(\rho \mathbf{u u})=-\nabla p+\mu \nabla^{2} \mathbf{u}+(\nabla \mu) \cdot\left[(\nabla u)+(\nabla u)^{T}\right]+\rho \mathbf{g}+\mathbf{f}
$$

A forma da equação de momento que efetivamente foi utilizada neste trabalho é dada por

$$
\frac{\partial \mathbf{u}}{\partial t}+\nabla \cdot(\mathbf{u u})=-\frac{1}{\rho} \nabla p+\frac{1}{\rho}\left[\mu \nabla^{2} \mathbf{u}+(\nabla \mu) \cdot\left[(\nabla u)+(\nabla u)^{T}\right]+\rho \mathbf{g}+\mathbf{f}\right] .
$$

A equação (2.12) encontra-se na forma não-conservativa para a propriedade $\rho$.

A força de campo f está ligada à tensão interfacial, agindo diretamente na interface entre dois ou mais fluidos presentes no escoamento. Esta força pode ser modelada de várias formas, dependendo da natureza física do problema em questão. Unverdi e Tryggvason [22] propõem o modelo:

$$
\mathbf{f}=\sigma_{I} \kappa \delta\left(x-x^{f}\right) \mathbf{n},
$$


onde $\sigma_{I}$ é o coeficiente de tensão interfacial, $\kappa$ é a curvatura (parâmetro geométrico), $\mathbf{n}$ é o vetor normal. A função $\delta\left(x-x^{f}\right)$ é uma função delta Dirac, onde $x^{f}$ é um ponto da interface e $x$ é um ponto qualquer do domínio discreto, não pertencente à interface.

Esta função $\delta$ satisfaz a propriedade

$$
\int_{-\infty}^{+\infty} f(s) \delta\left(s-s_{0}\right) d s=f\left(s_{0}\right)
$$

e, considera-se neste caso de escoamento, igual a zero, exceto na interface entre dois ou mais fluidos.

Sendo $C$ a curva definida pela interface, tem-se que $s=\left|x-x^{f}\right|=d(x, C)$ para algum $x^{f} \in C$, onde

$$
d(x, C)=\inf \left\{\left|x-x^{f}\right|: x^{f} \in C\right\}
$$

Ainda, esta função $\delta\left(x-x^{f}\right)$ pode ser vista como o limite de uma função suave, quando o parâmetro utilizado para a suavização da curva tende a zero. Um exemplo desta função pode ser visto em [19].

\subsection{Forma Bidimensional para as Equações de Navier- Stokes}

As equações que foram apresentadas até o momento estão na forma vetorial, onde independem do sistema de coordenadas utilizado. Uma vez que o objetivo deste trabalho é simular escoamentos multifásicos bidimensionais, a equação de conservação de momento e a da conservação da massa serão desenvolvidas no sistema bidimensional cartesiano, ou seja, onde $\mathbf{x}=(x, y)^{T}, \mathbf{u}=(u, v)^{T}, \mathbf{g}=\left(g_{x}, g_{y}\right)^{T}$ e $\mathbf{f}=\sigma_{I} \delta(s) \mathbf{n}=\sigma_{I} \delta(s)\left(n_{x}, n_{y}\right)^{T}$.

Logo, a equação de continuidade (2.8) neste sistema fica

$$
\frac{\partial u}{\partial x}+\frac{\partial v}{\partial y}=0
$$

Desenvolvendo cada termo da equação de conservação de momento, tem-se que

$$
\nabla \mathbf{u}=\left(\begin{array}{ll}
\frac{\partial u}{\partial x} & \frac{\partial u}{\partial y} \\
\frac{\partial v}{\partial x} & \frac{\partial v}{\partial y}
\end{array}\right)
$$

cuja transposta é 


$$
(\nabla \mathbf{u})^{\mathbf{T}}=\left(\begin{array}{ll}
\frac{\partial u}{\partial x} & \frac{\partial v}{\partial x} \\
\frac{\partial u}{\partial y} & \frac{\partial v}{\partial y}
\end{array}\right)
$$

Para o laplaciano de $\mathbf{u}, \nabla^{2} \mathbf{u}$, considere a identidade

$$
\nabla^{2} \mathbf{u}=\nabla(\nabla \cdot \mathbf{u})-\nabla \wedge(\nabla \wedge \mathbf{u})
$$

e, utilizando a condição de incompressibilidade (2.8), obtém-se

$$
\begin{gathered}
\nabla^{2} \mathbf{u}=-\nabla \wedge(\nabla \wedge \mathbf{u})= \\
=\left(\begin{array}{c}
\frac{\partial}{\partial y}\left(\frac{\partial u}{\partial x}-\frac{\partial v}{\partial y}\right) \\
\frac{\partial}{\partial x}\left(\frac{\partial u}{\partial y}-\frac{\partial v}{\partial x}\right)
\end{array}\right)= \\
=\left(\begin{array}{c}
\frac{\partial}{\partial x}\left(\frac{\partial u}{\partial x}+\frac{\partial v}{\partial y}\right)-\frac{\partial^{2} u}{\partial x^{2}}-\frac{\partial^{2} u}{\partial y^{2}} \\
\frac{\partial}{\partial y}\left(\frac{\partial u}{\partial x}+\frac{\partial v}{\partial y}\right)-\frac{\partial^{2} v}{\partial x^{2}}-\frac{\partial^{2} v}{\partial y^{2}}
\end{array}\right)
\end{gathered}
$$

donde, novamente utilizando a condição de incompressibilidade, obtém-se

$$
\nabla^{2} \mathbf{u}=\left(\begin{array}{c}
\frac{\partial^{2} u}{\partial x^{2}}+\frac{\partial^{2} u}{\partial y^{2}} \\
\frac{\partial^{2} v}{\partial x^{2}}+\frac{\partial^{2} v}{\partial y^{2}}
\end{array}\right)
$$

Por fim, as equações de conservação de momento nas direções $x$ e $y$, respectivamente, ficam

$$
\frac{\partial u}{\partial t}=-\frac{\partial u^{2}}{\partial x}-\frac{\partial u v}{\partial y}-\frac{1}{\rho} \frac{\partial p}{\partial x}+\frac{1}{\rho}\left[\mu\left(\frac{\partial^{2} u}{\partial x^{2}}+\frac{\partial^{2} u}{\partial y^{2}}\right)+2 \frac{\partial \mu}{\partial x} \frac{\partial u}{\partial x}+\frac{\partial \mu}{\partial y}\left(\frac{\partial u}{\partial y}+\frac{\partial v}{\partial x}\right)+\rho g_{x}+\sigma \kappa \delta(s) n_{x}\right]
$$

$$
\frac{\partial v}{\partial t}=-\frac{\partial v^{2}}{\partial y}-\frac{\partial u v}{\partial x}-\frac{1}{\rho} \frac{\partial p}{\partial y}+\frac{1}{\rho}\left[\mu\left(\frac{\partial^{2} v}{\partial x^{2}}+\frac{\partial^{2} v}{\partial y^{2}}\right)+2 \frac{\partial \mu}{\partial y} \frac{\partial v}{\partial y}+\frac{\partial \mu}{\partial x}\left(\frac{\partial u}{\partial y}+\frac{\partial v}{\partial x}\right)+\rho g_{y}+\sigma \kappa \delta(s) n_{y}\right]
$$

\subsection{Condições de Contorno}

As equações para escoamento multifásico discutidas anteriormente necessitam de condições apropriadas para se ter uma formulação correta do problema. A especificação 
correta destas condições é fundamental para se obter uma solução numérica coerente com o problema em questão. No caso, tem-se que

- As condições de fronteira para os contornos rígidos, aplica-se, neste caso bidimensional de escoamento multifásico, a condição no-slip. Esta condição considera que o fluido imediatamente adjacente à superfície sólida deve estar em repouso em relação a mesma. É também denominada como condição de aderência completa, onde as componentes normal $u_{n}$ e tangencial $u_{t}$ da velocidade nesta superfície sólida são definidas como nulas.

Existe ainda a condição de fronteira free-slip que permite que o fluido deslize livremente sobre a superfície sólida. É também aplicada em problemas onde há um plano de simetria. Define-se, neste caso, a componete normal nula e $\frac{\partial u_{t}}{\partial n}=0$ para as componentes tangenciais, onde $n$ é a direção normal à superfície da fronteira.

- A condição inicial para a velocidade determina um campo de velocidade em $t=0$ para todo o domínio, e deve satisfazer a equação da continuidade (2.8).

- As condições de contorno para a pressão e velocidade na superfície livre são:

$$
(S \cdot \mathbf{n}) \cdot \mathbf{m}=0
$$

$$
(S \cdot \mathbf{n}) \cdot \mathbf{n}=p_{c a p}
$$

onde $p_{c a p}$ é a pressão capilar, $n=\left(n_{x}, n_{y}\right)$ é o vetor unitário normal externo à superfície, e $m=\left(m_{x}, m_{y}\right)$ é o vetor unitário tangente à superfície, como ilustra a figura (2.2).

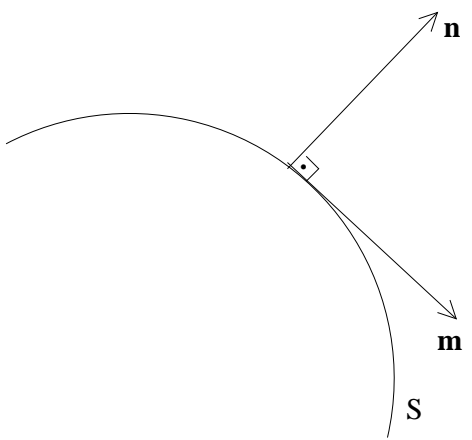

Figura 2.2: Posição dos vetores normal e tangencial numa superfície livre ou interface

Considere o tensor de tensão $S$, 


$$
S=-p I+\tau
$$

onde $\tau$, considerando a condição de incompressibilidade, é dada pela equação

$$
\tau=\mu\left[(\nabla u)+(\nabla u)^{T}\right]
$$

e a pressão capilar $p_{c a p}$ da superfície ou interface é dada por

$$
p_{c a p}=\sigma \kappa
$$

O tensor $S$ pode ser escrito como

$$
S=\left(\begin{array}{cc}
-p & 0 \\
0 & -p
\end{array}\right)+\left(\begin{array}{cc}
2 \mu \frac{\partial u}{\partial x} & \mu\left(\frac{\partial u}{\partial y}+\frac{\partial v}{\partial x}\right) \\
\mu\left(\frac{\partial v}{\partial x}+\frac{\partial u}{\partial y}\right) & 2 \mu \frac{\partial v}{\partial y}
\end{array}\right)
$$

ou seja,

$$
S=\left(\begin{array}{ll}
-p+2 \mu \frac{\partial u}{\partial x} & \mu\left(\frac{\partial u}{\partial y}+\frac{\partial v}{\partial x}\right) \\
\mu\left(\frac{\partial v}{\partial x}+\frac{\partial u}{\partial y}\right) & -p+2 \mu \frac{\partial v}{\partial y} .
\end{array}\right)
$$

Dessa forma considerando os vetores $\mathbf{n}=\left(n_{x}, n_{y}\right)$ e $\mathbf{m}=\left(m_{x}, m_{y}\right)$, a equação $(2.24)$ fica

$(S \cdot \mathbf{n}) \cdot \mathbf{m}=-p\left(n_{x} m_{x}+n_{y} m_{y}\right)+2 \mu \frac{\partial u}{\partial x} n_{x} m_{x}+2 \mu \frac{\partial v}{\partial y} n_{y} n_{x}+\mu\left(\frac{\partial u}{\partial y}+\frac{\partial v}{\partial x}\right)\left(n_{y} m_{x}+n_{x} m_{y}\right)$.

Como $\mathbf{m} \cdot \mathbf{n}=0$, segue que

$$
2 \frac{\partial u}{\partial x} n_{x} m_{x}+2 \frac{\partial v}{\partial y} n_{y} m_{x}+\left(\frac{\partial u}{\partial y}+\frac{\partial v}{\partial x}\right)\left(n_{y} m_{x}+n_{x} m_{y}\right)=0
$$

De modo análogo a equação (2.25) fica

$$
(S \cdot \mathbf{n}) \cdot \mathbf{n}=-p\left(n_{x}{ }^{2}+n_{y}{ }^{2}\right)+2 \mu\left[\frac{\partial u}{\partial x} n_{x}{ }^{2}+\left(\frac{\partial u}{\partial y}+\frac{\partial v}{\partial x}\right) n_{x} n_{y}+\frac{\partial v}{\partial y} n_{y}{ }^{2}\right] .
$$

Como n.n $=1$, segue que

$$
-p+2 \mu\left[\frac{\partial u}{\partial x} n_{x}^{2}+\left(\frac{\partial u}{\partial y}+\frac{\partial v}{\partial x}\right) n_{x} n_{y}+\frac{\partial v}{\partial y} n_{y}^{2}\right]=\sigma \kappa
$$


As equações (2.27) e (2.28), são as condições de contorno para a superfície livre do fluido.

Numa interface entre duas fases (A) e (B), por exemplo, as condições para a pressão e velocidade são:

$$
\begin{gathered}
\left(\tau_{A} \cdot n\right) \cdot m=\left(\tau_{B} \cdot n\right) \cdot m ; \\
\left(\tau_{A} \cdot n\right) \cdot n=\left(\tau_{B} \cdot n\right) \cdot n+p_{c a p} .
\end{gathered}
$$

Estas condições são chamadas de condições de acoplamento, porém as condições para pressão e velocidade na interface virão diretamente das equações de conservação de momento (2.17) e da continuidade (2.8), considerando o termo fonte $\mathbf{f}=\sigma \kappa \delta(s) \mathbf{n}$, devido às forças de tensão interfacial.

\subsection{Forma Adimensional}

Em problemas de mecânica dos fluidos, as propriedades do escoamento e dos fluidos envolvidos podem ser caracterizados por grandezas específicas. Essas propriedades dimensionais podem ser agrupadas em parâmetros de adimensionalização, os quais passam a caracterizar um escoamento. A importância de lidar com problemas onde as equações estão adimensionalisadas está intimamente ligada ao fato de se poder trabalhar com modelos onde a geometria difere apenas nas escalas (similaridade), possibilitanto e garantindo que o comportamento que se quer simular é o mesmo que se observaria na prática. Assim, se num escoamento as equações de movimento estiverem adimensionalisadas e forem similares, então são irrelevantes as dimensões.

Neste trabalho utiliza-se os seguintes parâmetros de adimensionalização:

- Número de Reynolds (Re): É a razão entre as forças inerciais e as forças viscosas, ou seja:

$$
R e=\frac{\rho_{0} L_{0} V_{0}}{\mu_{0}}
$$

onde $\rho_{0}, L_{0}, V_{0}$ e $\mu_{0}$ são os valores de referência de densidade, comprimento, velocidade e viscosidade, respectivamente. 
O número de Reynolds serve para indicar se o escoamento é laminar (abaixo de um Re crítico) ou turbulento (caso contrário), passando por uma faixa de transição entre laminar e turbulento.

- Número de Froude $(F r)$ : É a razão entre as forças inerciais e as forças gravitacionais, ou seja:

$$
F r^{2}=\frac{V_{0}^{2}}{g L_{0}}
$$

O número de Froude, caracteriza escoamentos cuja gravidade, g, tem papel importante, como é o caso de escoamentos incompressíveis com superfícies livres.

- Número de Weber $(W e)$ : É a razão entre as forças inerciais e forças de tensão superficial, ou seja,

$$
W e=\frac{\rho_{0} L_{0} V_{0}^{2}}{\sigma}
$$

Este parâmetro é importante em escoamentos com tensões superficial e interfacial.

Os parâmetros de adimensionalização (2.30) e (2.31) surgem da adimensionalização dos termos fontes das equações de momento.

\subsubsection{Adimensionalização das Equações de momento e condição de incompressibilidade}

Para adimensionalizar as equações de conservação de momento e da continuidade é possível adotar as seguintes variáveis adimensionais, válidas para escoamentos incompressíveis:

$$
\begin{gathered}
\rho=\bar{\rho} \rho_{0} ; \quad \mu=\bar{\mu} \mu_{0} ; \\
p=\bar{p} \rho_{0} U_{0}^{2} ; \quad u=\bar{u} U_{0} ; \\
v=\bar{v} U_{0} ; \quad g=\bar{g} \mathbf{g} \\
x=\bar{x} L_{0} ; \quad y=\bar{y} L_{0} ;
\end{gathered}
$$




$$
\begin{gathered}
t=\frac{L_{0}}{U_{0}} \bar{t} ; \quad \kappa=\frac{\bar{\kappa}}{L_{0}} ; \\
R=\bar{R} L_{0} ; \quad \sigma=\bar{\sigma} \rho_{0} L_{0} U_{0}{ }^{2} .
\end{gathered}
$$

Substituindo estas variáveis na equação de momento, na direção $x$, tem-se

$$
\begin{aligned}
& \frac{\partial \bar{\rho} \rho_{0} \bar{u} U_{0}}{\partial \frac{L_{0}}{U_{0}} \bar{t}}+\frac{\partial \bar{\rho} \rho_{0} \bar{u}^{2} U_{0}^{2}}{\partial \bar{x} L_{0}}+\frac{\partial \bar{\rho} \rho_{0} \bar{u} U_{0} \bar{v} U_{0}}{\partial \bar{y} L_{0}}=-\frac{\partial \bar{p} \rho_{0} U_{0}^{2}}{\partial \bar{x} L_{0}}+\bar{\mu} \mu_{0}\left(\frac{\partial^{2} \bar{u} U_{0}}{\partial \bar{x}^{2} L_{0}^{2}}+\frac{\partial^{2} \bar{u} U_{0}}{\partial \bar{y}^{2} L_{0}^{2}}\right) \\
& +2 \frac{\partial \bar{\mu} \mu_{0}}{\partial \bar{x} L_{0}} \frac{\partial \bar{u} U_{0}}{\partial \bar{x} L_{0}}+\frac{\partial \bar{\mu} \mu_{0}}{\partial \bar{y} L_{0}}\left(\frac{\partial \bar{v} U_{0}}{\partial \bar{x} L_{0}}+\frac{\partial \bar{u} U_{0}}{\partial \bar{y} L_{0}}\right)+\bar{\rho} \rho_{0} \bar{g}_{x} g_{0}+\bar{\sigma} \sigma_{0} \frac{\bar{\kappa}}{L_{0}} \frac{\bar{\delta}}{L_{0}}\left(\bar{x}-\bar{x}^{f}\right) n_{x}
\end{aligned}
$$

ou seja,

$$
\begin{gathered}
\frac{\rho_{0} U_{0}^{2}}{L_{0}} \frac{\partial \overline{\rho u}}{\partial \bar{t}}+\frac{\rho_{0} U_{0}^{2}}{L_{0}} \frac{\partial \overline{\rho u}^{2}}{\partial \bar{x}}+\frac{\rho_{0} U_{0}^{2}}{L_{0}} \frac{\partial \overline{\rho u v}}{\partial \bar{y}}=-\frac{\rho_{0} U_{0}^{2}}{L_{0}} \frac{\partial \bar{p}}{\partial \bar{x}}+\frac{\mu_{0} U_{0}}{L_{0}^{2}} \bar{\mu}\left(\frac{\partial^{2} \bar{u}}{\partial \bar{x}^{2}}+\frac{\partial^{2} \bar{u}}{\partial \bar{y}^{2}}\right) \\
+\frac{\mu_{0} U_{0}}{L_{0}^{2}}\left[2 \frac{\partial \bar{\mu}}{\partial \bar{x}} \frac{\partial \bar{u}}{\partial \bar{x}}+\frac{\partial \bar{\mu}}{\partial \bar{y}}\left(\frac{\partial \bar{v}}{\partial \bar{x}}+\frac{\partial \bar{u}}{\partial \bar{y}}\right)\right]+\rho_{0} g_{0} \overline{\rho g}_{x}+\frac{\sigma_{0}}{L_{0}^{2}} \overline{\sigma \kappa} \bar{\delta}\left(\bar{x}-\bar{x}^{f}\right) n_{x}
\end{gathered}
$$

simplificando,

$$
\begin{gathered}
\frac{\partial \overline{\rho u}}{\partial \bar{t}}+\frac{\partial \overline{\rho u}^{2}}{\partial \bar{x}}+\frac{\partial \overline{\rho u v}}{\partial \bar{y}}=-\frac{\partial \bar{p}}{\partial \bar{x}}+\frac{\mu_{0}}{\rho_{0} U_{0}^{2} L_{0}} \bar{\mu}\left(\frac{\partial^{2} \bar{u}}{\partial \bar{x}^{2}}+\frac{\partial^{2} \bar{u}}{\partial \bar{y}^{2}}\right) \\
+\frac{\mu_{0}}{\rho_{0} U_{0}^{2} L_{0}}\left[2 \frac{\partial \bar{\mu}}{\partial \bar{x}} \frac{\partial \bar{u}}{\partial \bar{x}}+\frac{\partial \bar{\mu}}{\partial \bar{y}}\left(\frac{\partial \bar{v}}{\partial \bar{x}}+\frac{\partial \bar{u}}{\partial \bar{y}}\right)\right]+\frac{g_{0} L_{0}}{U_{0}} \overline{\rho g}_{x}+\frac{\sigma_{0}}{\rho_{0} L_{0}^{2} U_{0}^{2}} \overline{\sigma \kappa} \bar{\delta}\left(\bar{x}-\bar{x}^{f}\right) n_{x} .
\end{gathered}
$$

Utilizando o número de Reynolds, Froude e Weber, e eliminando as barras para simplificar a notação, obtém-se

$$
\begin{gathered}
\frac{\partial \rho u}{\partial t}+\frac{\partial \rho u^{2}}{\partial x}+\frac{\partial \rho u v}{\partial y}=-\frac{\partial p}{\partial x}+\frac{1}{R e} \mu\left(\frac{\partial^{2} u}{\partial x^{2}}+\frac{\partial^{2} u}{\partial y^{2}}\right) \\
+\frac{1}{R e}\left[2 \frac{\partial \mu}{\partial x} \frac{\partial u}{\partial x}+\frac{\partial \mu}{\partial y}\left(\frac{\partial v}{\partial x}+\frac{\partial u}{\partial y}\right)\right]+\frac{1}{F r^{2}} \rho g_{x}+\frac{1}{W e} \sigma \kappa \delta\left(x-x^{f}\right) n_{x}
\end{gathered}
$$

De modo análogo, efetuando-se os cálculos para a equação de momento na direção $y$, obtém-se

$$
\frac{\partial \rho v}{\partial t}+\frac{\partial \rho u v}{\partial x}+\frac{\partial \rho v^{2}}{\partial y}=-\frac{\partial p}{\partial y}+\frac{1}{R e} \mu\left(\frac{\partial^{2} v}{\partial v^{2}}+\frac{\partial^{2} u}{\partial y^{2}}\right)
$$




$$
+\frac{1}{R e}\left[2 \frac{\partial \mu}{\partial y} \frac{\partial v}{\partial y}+\frac{\partial \mu}{\partial x}\left(\frac{\partial u}{\partial y}+\frac{\partial v}{\partial x}\right)\right]+\frac{1}{F r^{2}} \rho g_{y}+\frac{1}{W e} \sigma \kappa \delta\left(x-x^{f}\right) n_{y}
$$

Adimensionalizando a condição de incompressibilidade (2.8), obtém-se

$$
\frac{\partial \bar{u} U_{0}}{\partial \bar{x} L_{0}}+\frac{\partial \bar{v} U_{0}}{\partial \bar{y} L_{0}}=0
$$

ou seja,

$$
\frac{\partial u}{\partial x}+\frac{\partial v}{\partial y}=0
$$

A forma adimensional não-conservativa fica então

$\frac{\partial \mathbf{u}}{\partial t}+\nabla \cdot(\mathbf{u u})=\frac{1}{\rho}\left\{-\nabla p+\frac{\mu}{R e} \nabla^{2} \mu+\frac{1}{R e}(\nabla \mu) \cdot\left[(\nabla \mathbf{u})+(\nabla \mathbf{u})^{T}\right]+\frac{1}{F r^{2}} \rho \mathbf{g}+\frac{1}{W e} \kappa \delta\left(x-x^{f}\right) \mathbf{n}\right\}$.

Portanto, as equações (2.32), (2.33) e (2.34), são as equações adimensionais de conservação de momento e conservação de massa, respectivamente. A equação de conservação de momento (2.35) é a forma adimensional não-conservativa em $\rho$.

\subsubsection{Adimensionalização das Equações de Condições de Con- torno na Superfície Livre}

Substituindo as propriedades de adimensionalizacão em (2.27), obtém-se

$$
2 \bar{\mu} \mu_{0} \frac{\partial \bar{u} U_{0}}{\partial \bar{x} L_{0}} n_{x} n_{y}+\bar{\mu} \mu_{0}\left(\frac{\partial \bar{u} U_{0}}{\partial \bar{y} U_{0}}+\frac{\partial \bar{v} U_{0}}{\partial \bar{x} L_{0}}\right)\left(n_{x}{ }^{2}-n_{y}{ }^{2}\right)+2 \bar{\mu} \mu_{0} \frac{\partial \bar{v} U_{0}}{\partial \bar{y} L_{0}} n_{x} n_{y}=0
$$

ou seja,

$$
\frac{\mu_{0} U_{0}}{L_{0}} 2 \bar{\mu} \frac{\partial \bar{u}}{\partial \bar{x}} n_{x} n_{y}+\frac{\mu_{0} U_{0}}{L_{0}} \bar{\mu}\left(\frac{\partial \bar{u}}{\partial \bar{y}}+\frac{\mu_{0} U_{0}}{L_{0}} \frac{\partial \bar{v}}{\partial \bar{x}}\right)\left(n_{x}{ }^{2}-n_{y}{ }^{2}\right)+\frac{\mu_{0} U_{0}}{L_{0}} 2 \bar{\mu} \frac{\partial \bar{v}}{\partial \bar{y}} n_{x} n_{y}=0
$$

simplificando,

$$
2 \mu \frac{\partial u}{\partial x} n_{x} n_{y}+\mu\left(\frac{\partial u}{\partial y}+\frac{\partial v}{\partial x}\right)\left(n_{x}^{2}-n_{y}^{2}\right)+\mu \frac{\partial v}{\partial y} n_{x} n_{y}=0
$$


Para adimensionalizar a condição de contorno (2.28), observe que $\mu=\rho \nu$, onde $\nu$ é o coeficiente de viscosidade cinemática do fluido.

Assim, tem-se

$-\bar{p} \rho_{0} U_{0}{ }^{2}\left(n_{x}{ }^{2}+n_{y}{ }^{2}\right)+2 \bar{\rho} \rho_{0} \bar{\nu} \nu_{0}\left[\frac{\partial \bar{u} U_{0}}{\partial \bar{x} L_{0}} n_{x}{ }^{2}+\left(\frac{\partial \bar{u} U_{0}}{\partial \bar{y} L_{0}}+\frac{\partial \bar{v} U_{0}}{\partial \bar{x} L_{0}}\right) n_{x} n_{y}+\frac{\partial \bar{v} U_{0}}{\partial \bar{y} L_{0}} n_{y}{ }^{2}\right]=\bar{\sigma} \rho_{0} U_{0}^{2} L_{0} \frac{\bar{\kappa}}{L_{0}}$ ou seja,

$$
-\rho_{0}{U_{0}}^{2} \bar{p}\left(n_{x}{ }^{2}+n_{y}{ }^{2}\right)+\frac{\rho_{0} \nu_{0} U_{0}}{L_{0}} 2 \overline{\rho \nu}\left[\frac{\partial \bar{u}}{\partial \bar{x}} n_{x}{ }^{2}+\left(\frac{\partial \bar{u}}{\partial \bar{y}}+\frac{\partial \bar{v}}{\partial \bar{x}}\right) n_{x} n_{y}+\frac{\partial \bar{v}}{\partial \bar{y}} n_{y}{ }^{2}\right]=\rho_{0} U_{0}^{2} \overline{\sigma \kappa}
$$

simplificando,

$$
-\bar{p}\left(n_{x}^{2}+n_{y}{ }^{2}\right)+\frac{\nu_{0}}{L_{0} U_{0}} 2 \overline{\rho \nu}\left[\frac{\partial \bar{u}}{\partial \bar{x}} n_{x}^{2}+\left(\frac{\partial \bar{u}}{\partial \bar{y}}+\frac{\partial \bar{v}}{\partial \bar{x}}\right) n_{x} n_{y}+\frac{\partial \bar{v}}{\partial \bar{y}} n_{y}{ }^{2}\right]=\bar{\sigma} \frac{1}{R}
$$

ou ainda,

$$
-p\left(n_{x}{ }^{2}+n_{y}{ }^{2}\right)+\frac{1}{R e} 2 \mu\left[\frac{\partial u}{\partial x} n_{x}{ }^{2}+\left(\frac{\partial u}{\partial y}+\frac{\partial v}{\partial x}\right) n_{x} n_{y}+\frac{\partial v}{\partial y} n_{y}{ }^{2}\right]=\frac{1}{W e} \frac{1}{R} .
$$

Portanto, as equações (2.36) e (2.37) são as equações de condição de contorno de superfície livre adimensionais.

\subsection{Cálculo da Curvatura}

Uma abordagem para se avaliar os efeitos da tensão superficial e interfacial está baseada no cálculo de (2.26). Para isto, precisa-se estimar o raio de curvatura $R$ da interface em cada célula.

Isto pode ser feito utilizando-se um ajuste por minimos quadrados, aproximando-se a superfície livre ou interface local por um arco de circunferência [5] e obtendo-se assim uma estimativa da curvatura, figura (2.3).

A equação da circunferência de centro $\left(x_{0}, y_{0}\right)$ e raio $R$ é dada por

$$
\left(x-x_{0}\right)^{2}+\left(y-y_{0}\right)^{2}=R^{2}
$$




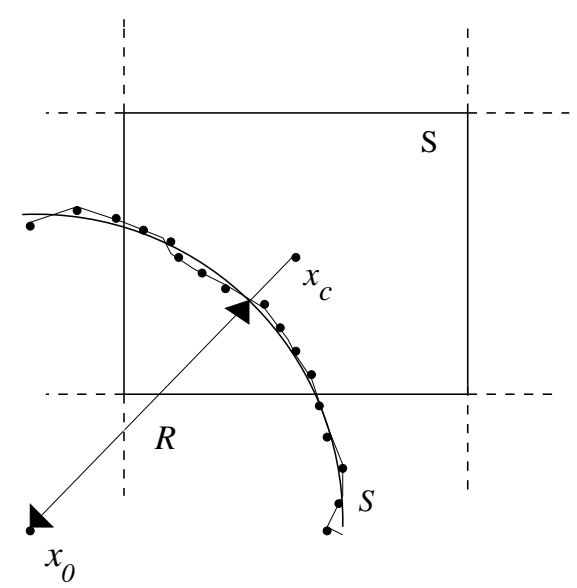

Figura 2.3: Aproximação de uma superfície pelo método dos mínimos quadrados

ou seja,

$$
x^{2}-2 x x_{0}+y^{2}-2 y y_{0}+x_{0}^{2}+y_{0}^{2}=R^{2} .
$$

Fazendo, $a=x_{0}, b=y_{0}, c=R^{2}-x_{0}{ }^{2}-y_{0}{ }^{2}$, tem-se que (2.39) fica

$$
2 a x+2 b y+c=x^{2}+y^{2}
$$

Dessa forma, determinando-se $a, b$ e $c$, determina-se a equação da circunferência que melhor aproxima a curvatura da superfície livre ou interface local.

Sejam $x=\left(x_{i}, y_{i}\right)^{T}, i=1, \ldots, n$, partículas em uma vizinhança da superfície ou numa interface.

Assim, de (2.38), segue que a seguinte equação para cada $x_{i}$ é dada por

$$
2 a x_{i}+2 b y_{i}+c=x_{i}^{2}+y_{i}^{2} .
$$

Pelo método dos mínimos quadrados, tem-se

$$
\phi_{0}=\left(\begin{array}{c}
2 x_{1} \\
2 x_{2} \\
\vdots \\
2 x_{n}
\end{array}\right), \phi_{1}=\left(\begin{array}{c}
2 y_{1} \\
2 y_{2} \\
\vdots \\
2 y_{n}
\end{array}\right), \phi_{2}=\left(\begin{array}{c}
1 \\
1 \\
\vdots \\
1
\end{array}\right) \mathrm{e}
$$




$$
f=\left(\begin{array}{c}
x_{1}{ }^{2}+y_{1}{ }^{2} \\
x_{2}{ }^{2}+y_{2}{ }^{2} \\
\vdots \\
x_{n}{ }^{2}+y_{n}{ }^{2}
\end{array}\right) \text {. }
$$

Assim, obtém-se o seguinte sistema

$$
\left(\begin{array}{ccc}
<\phi_{0}, \phi_{0}> & <\phi_{0}, \phi_{1}> & <\phi_{0}, \phi_{2}> \\
<\phi_{1}, \phi_{0}> & <\phi_{1}, \phi_{1}> & <\phi_{1}, \phi_{2}> \\
<\phi_{2}, \phi_{0}> & <\phi_{2}, \phi_{1}> & <\phi_{2}, \phi_{2}>
\end{array}\right)\left(\begin{array}{c}
a \\
b \\
c
\end{array}\right)=\left(\begin{array}{c}
<\phi_{0}, f> \\
<\phi_{1}, f> \\
<\phi_{2}, f>
\end{array}\right)
$$

onde $\langle\mathbf{x}, \mathbf{y}\rangle$ é o produto escalar entre dois vetores, $\mathbf{x}$ e $\mathbf{y}$ em $\mathbb{R}^{n}$.

Se a matriz dos coeficientes acima é não singular, é possível determinar as constantes $a, b$ e $c$. Portanto, a curvatura $\kappa$ fica

$$
\kappa=\frac{1}{R}
$$

onde $R=\sqrt{c+a^{2}+b^{2}}$.

Se a matriz dos coeficientes acima é singular, então toma-se $\kappa=0$. 


\section{Capítulo 3}

\section{Cálculo da Velocidade e Pressão}

\subsection{Introdução}

Este capítulo apresenta o procedimento utilizado para o cálculo da velocidade e pressão, baseado no método GENSMAC (Generalized-Simplified-Marker-and-Cell) desenvolvido por Tomé e Mckee [23].

\subsection{Procedimento do Cálculo da Velocidade e Pressão}

Em linhas gerais, a idéia central do método GENSMAC é resolver explicitamente as equações de Navier-Stokes para escoamento incompressível com superfície livre em domínios arbitrários sobre os quais especifica-se as condições no-slip e free-slip nas fronteiras. As características deste método são :

- Utiliza partículas marcadoras (ou virtuais) para definir a posição da superfície livre, tais como os métodos MAC, desenvolvidos por Harlow e Welch [26], e o SMAC desenvolvido por Amsden e Harlow [2];

- A atualização do campo de escoamento é divida em duas partes: uma para o campo de velocidade e outra para o campo de pressão, de modo que não exista processo iterativo envolvendo esses dois campos.

Para atualizar o campo de velocidade e pressão, no caso de escoamento multifásico, pode-se seguir a idéia central e as características do método GENSMAC.

Assim, seja um tempo $t_{0}$ inicial. O campo de velocidade $\mathbf{u}\left(\mathbf{x}, t_{0}\right)$ é conhecido e as condições de fronteira para a velocidade e pressão são dadas. 
O campo de velocidade $\mathbf{u}(\mathbf{x}, t)$ no tempo $t=t_{0}+\delta t$, é calculado da seguinte forma: i) Seja $\tilde{p}\left(x, t_{0}\right)$ o campo de pressão arbitrária o qual satisfaz a condição de pressão correta na superfície livre.

ii) Calcula-se o campo de velocidade intermediária, $\tilde{\mathbf{u}}(\mathbf{x}, t)$, integrando no tempo a equação de conservação de momento (3.1)

$$
\begin{aligned}
& \frac{\partial \tilde{\mathbf{u}}}{\partial t}+\nabla \cdot(\mathbf{u u})= \\
& \left.-\frac{1}{\rho} \nabla \tilde{p}+\frac{\mu}{R e} \nabla^{2} \mathbf{u}+\frac{1}{R e}(\nabla \mu) \cdot\left[(\nabla \mathbf{u})+(\nabla \mathbf{u})^{T}\right]+\frac{1}{F r^{2}} \rho \mathbf{g}+\frac{\kappa}{W e} \delta\left(x-x^{f}\right) \mathbf{n}\right](3.1)
\end{aligned}
$$

desde que, no tempo $t=t_{0}, \tilde{\mathbf{u}}\left(\mathbf{x}, t_{0}\right)=\mathbf{u}\left(\mathbf{x}, t_{0}\right)$ e $p(\mathbf{x}, t)$ satisfaçam as equações de conservação de momento (2.35).

Subtraindo (3.1) de (2.35), obtém-se

$$
\frac{\partial \mathbf{u}}{\partial t}-\frac{\partial \tilde{\mathbf{u}}}{\partial t}=-\frac{1}{\rho}(\nabla p-\nabla \tilde{p})
$$

$\mathrm{Ou}$

$$
\frac{\partial}{\partial t}(\mathbf{u}-\tilde{\mathbf{u}})=-\frac{1}{\rho}[\nabla(p-\tilde{p})] .
$$

Aplicando o operador $\nabla$ em ambos os lados de (3.2) tem-se

$$
\nabla \cdot \frac{\partial}{\partial t}(\mathbf{u}-\tilde{\mathbf{u}})=-\nabla \cdot \frac{1}{\rho} \nabla(p-\tilde{p})
$$

ou seja,

$$
\frac{\partial}{\partial t}(\nabla \cdot \mathbf{u}-\nabla \cdot \tilde{\mathbf{u}})=-\nabla \cdot \frac{1}{\rho} \nabla(p-\tilde{p}) .
$$

Como $\nabla \cdot \mathbf{u}=0$, segue da equação (3.3), que

$$
\frac{\partial}{\partial t}(\nabla \cdot \tilde{\mathbf{u}})=\nabla \cdot \frac{1}{\rho} \nabla(p-\tilde{p}) .
$$

Discretizando a derivada temporal desta equação, tem-se:

$$
\frac{\nabla \cdot \tilde{\mathbf{u}}^{n+1}-\nabla \cdot \tilde{\mathbf{u}}^{n}}{\delta t}=\nabla \cdot \frac{1}{\rho} \nabla(p-\tilde{p}),
$$


onde $\delta t$ é o passo no tempo.

Utilizando a equação da compressibilidade e o fato de que $\tilde{\mathbf{u}}\left(\mathbf{x}, t_{0}\right)=\mathbf{u}\left(\mathbf{x}, t_{0}\right)$, segue que $\nabla \cdot \tilde{\mathbf{u}}^{n}=\nabla \cdot \mathbf{u}^{n}=0$

Logo,

$$
\nabla \cdot \tilde{\mathbf{u}}^{n+1}=\nabla \cdot \frac{1}{\rho} \delta t \nabla(p-\tilde{p})
$$

Definindo

$$
\psi(\mathbf{x}, t)=\delta t(p-\tilde{p})
$$

tem-se, dessa forma, a equação elíptica para $\psi$, dada por

$$
\nabla \cdot \frac{1}{\rho} \nabla \psi=\nabla \cdot \tilde{\mathbf{u}}
$$

Agora, discretizando a derivada temporal de (2.35) e (3.1), obtem-se

$\left.\frac{\mathbf{u}^{n+1}-\mathbf{u}^{n}}{\Delta t}=-\frac{1}{\rho} \nabla p+\frac{\mu}{R e} \nabla^{2} \mathbf{u}+\frac{1}{R e}(\nabla \mu) \cdot\left[(\nabla \mathbf{u})+(\nabla \mathbf{u})^{T}\right]+\frac{1}{F r^{2}} \rho \mathbf{g}+\frac{\kappa}{W e} \delta\left(x-x^{f}\right) \mathbf{n}\right]$

$\left.\frac{\tilde{\mathbf{u}}^{n+1}-\tilde{\mathbf{u}}^{n}}{\Delta t}=-\frac{1}{\rho} \nabla \tilde{p}+\frac{\mu}{R e} \nabla^{2} \mathbf{u}+\frac{1}{R e}(\nabla \mu) \cdot\left[(\nabla \mathbf{u})+(\nabla \mathbf{u})^{T}\right]+\frac{1}{F r^{2}} \rho \mathbf{g}+\frac{\kappa}{W e} \delta\left(x-x^{f}\right) \mathbf{n}\right]$.

Subtraindo (3.7) de (3.6), obtém-se

$$
\mathbf{u}^{n+1}-\tilde{\mathbf{u}}^{n+1}=-\frac{1}{\rho} \Delta t \nabla(p-\tilde{p})
$$

ou seja,

$$
\mathbf{u}-\tilde{\mathbf{u}}=-\frac{1}{\rho} \nabla \psi
$$

onde $\mathbf{u}=\mathbf{u}(\mathbf{x}, \mathrm{t})$ é o vetor campo de velocidade atualizado.

iii) Condições de Fronteira para $\psi$ :

Condição (homogênea) de Newmann: 


$$
\frac{\partial \psi}{\partial n}=0, \text { sobre a superfície rígida. }
$$

Condição (homogênea) de Dirichlet:

$$
\psi=0, \text { sobre a superfície livre. }
$$

iv) Cálculo da atualização da pressão:

O campo de pressão atualizado decorre diretamente da definição de equação elíptica para a função $\psi$ dada por (3.5), ou seja,

$$
p-\tilde{p}=\frac{\psi(\mathbf{x}, t)}{\delta t}
$$

O método, então, resolve a equação de momento, e a equação elíptica (3.5) (para a correção do campo de velocidade e pressão).

v) Atualização das partículas marcadoras:

Resolvendo-se a equação de conservação de momento, determina-se o campo de velocidade $\mathbf{u}$, utilizando-se de uma malha euleriana. Com isso, atualiza-se as posições das partículas marcadoras das interfaces ou superfícies livres integrando-se numericamente as equações $\frac{d x}{d t}=u$ e $\frac{d y}{d t}=v$.

Esta nova posição das partículas marcadoras será então utilizada para a reconstrução da superfície livre e interface que representam o fluido e permitem a visualização do escoamento. 


\section{Capítulo 4}

\section{Discretizações}

\subsection{Introdução}

Neste capítulo apresenta-se as discretizações das equações governantes para escoamentos multifásicos. Além disso, tem-se as discretizações das condições de contorno na superfície livre e na interface local, a discretização da equação elíptica para pressão e, finalmente, apresenta-se a aproximação da interface para a distribuição das forças devidas à tensão interfacial.

A discretização será feita utilizando-se o método de diferenças finitas em uma malha regular deslocada, onde se considera uma célula de dimensão $(\delta x, \delta y)$, cujas pressão $p_{i j}$, densidade $\left(\rho_{i j}\right)$, viscosidade $\mu_{i j}$ e a função $\psi_{i j}$, encontram-se posicionadas em seu centro. As velocidades $u_{i j}$ e $v_{i j}$ encontram-se nos pontos médios dos lados dessa célula, ou seja, nas posições $i \pm \frac{1}{2}$ e $j \pm \frac{1}{2}$, respectivamente, como ilustra a figura (4.1).

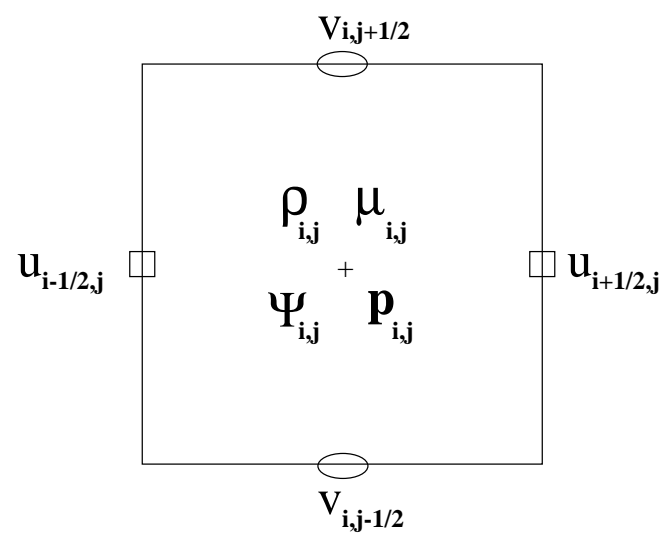

Figura 4.1: Configuração de uma Célula 
O método de diferenças finitas consite em aproximar as derivadas de uma função por diferenças desta função avaliadas em pontos conhecidos. Pode-se obter tal aproximação desenvolvendo, por exemplo, esta função em série de Taylor, ao redor de um ponto envolvido nesta aproximação. Como a série é infinita, isola-se o termo da derivada que possui a ordem que se quer aproximar.

\subsection{Definição das Células}

Como o fluido está continuamente em movimento, é utilizado um procedimento para identificar a região contendo fluido e a superfície livre, e também a interface. Para isto, tem-se a seguinte classificação global (para o fluido como um todo):

- Fronteira ou Boundary (B): células da malha tendo metade ou mais de seu volume contido no contorno rígido são assim classificadas.

- Injetor ou Inflow (I): células contendo a metade ou mais de seu volume em um injetor (células que representam a entrada do fluido na região de domínio do fluido).

- Ejetor ou Outflow $(\mathbf{O})$ : células contendo a metade ou mais de seu volume em um ejetor (células que representam a saída do fluido na região de domínio do fluido)

- Vazia ou Empty (E): células que não contém fluido.

- Superfície ou Surface (S): células que contém alguma porção da superfície do fluido (células que contém fluido e tem pelo menos uma adjacência com uma célula do tipo E, essas células contém a superfície livre).

- Cheia ou Full (F): células que contém fluido e não têm contato com células do tipo E.

Esta mesma classificação se aplica a cada uma das fases, separadamente, ou seja, para cada fase, uma célula irá ser S, E, F, I ou O. Na classificação global do escoamento como um todo, uma célula será de interface entre dois ou mais fluidos se esta é do tipo $\mathrm{S}$ ou $\mathrm{F}$ para mais de uma fase.

Por exemplo, uma célula pode ser $F_{1}$, cheia da fase 1 , e $E_{2}, E_{3}$, vazia da fase 2 e 3 , respectivamente, no caso de um escoamento com três fases. Se uma célula for $S_{1}$ e $S_{2}$, ela será uma célula de interface entre a fase 1 e 2 . Uma célula irá ser célula $S$ (global) apenas se for $\mathrm{S}$ para uma fase, e $\mathrm{E}_{i}$ para todas as outras fases $i$. Analogamente, uma célula irá ser E se for $\mathrm{E}_{i}$ para todas as fases $i$.

Note na figura (4.2) que as células interface entre as fases $i$ e $j$ aparecem identificadas 


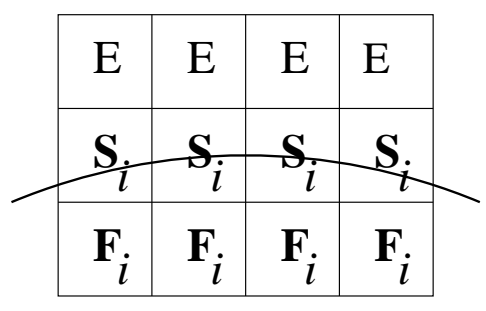

Fase i

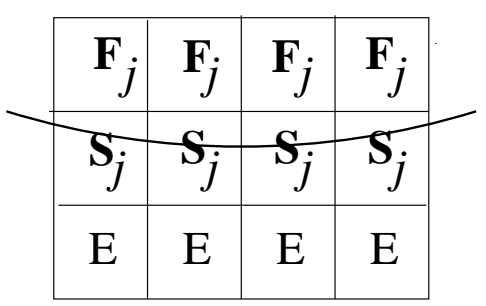

Fase j

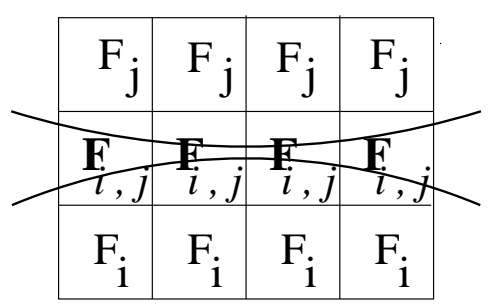

Fases i e j

Figura 4.2: Indentificação das células interfaces entre as fases $i$ e $j$

como $\mathrm{F}_{i, j}$. Isto ocorre porque na identificação global das células, esta é uma célula que não tem contato com célula do tipo E.

\subsection{Discretizações das Equações de Momento}

Considere a equação de momento adimensional na direção $x$ :

$$
\frac{\partial u}{\partial t}+\operatorname{Conv}(u)=-\frac{1}{\rho} \frac{\partial p}{\partial x}+V_{i s c_{1}}(u)+V i s c_{2}(u)+\frac{1}{F r^{2}} g_{x}+\frac{\sigma_{I} \kappa}{\rho W e} \delta(s) n_{x},
$$

onde

$$
\begin{aligned}
\operatorname{Conv}(u) & =\frac{\partial u^{2}}{\partial x}+\frac{\partial(v u)}{\partial y} \\
\operatorname{Visc}_{1}(u) & =\frac{\mu}{\rho R e}\left(\frac{\partial^{2} u}{\partial x^{2}}+\frac{\partial^{2} u}{\partial y^{2}}\right) \\
\operatorname{Visc}_{2}(u) & =\frac{1}{\rho R e}\left[2 \frac{\partial \mu}{\partial x} \frac{\partial u}{\partial x}+\frac{\partial \mu}{\partial y}\left(\frac{\partial v}{\partial x}+\frac{\partial u}{\partial y}\right)\right]
\end{aligned}
$$

são os termos convectivo e viscosos, respectivamente.

A equação (4.1) será discretizada termo-a-termo, segundo a técnica de discretização por difereças finitas, no ponto $\left(i+\frac{1}{2}, j\right)$ da célula.

\section{- Discretização da derivada temporal}

Para a deriva temporal, utiliza-se diferença progressiva de primeira ordem, ou seja

$$
\left.\frac{\partial u}{\partial t}\right|_{i+\frac{1}{2}, j}=\frac{u_{i+\frac{1}{2}, j}^{n+1}-u_{i+\frac{1}{2}, j}^{n}}{\delta t}
$$


onde $\delta t$ é o passo no tempo.

Como todos os outros termos da equação serão discretizados no tempo $n$, tem-se, portanto, uma discretização explícita. Logo, para simplificar a notação, o índice $n$ das aproximações de todos os outros termos será omitido.

\section{- Discretização do gradiente de pressão}

O gradiente de pressão é discretizado por diferenças centrais, ou seja

$$
\left.\frac{1}{\rho} \frac{\partial p}{\partial x}\right|_{i+\frac{1}{2}, j}=\frac{1}{\rho_{i+\frac{1}{2}, j}} \frac{p_{i+1, j}-p_{i, j}}{\delta x},
$$

Note que a densidade $\rho$ não está definida no ponto $\left(i+\frac{1}{2}, j\right)$, pois seu valor é estimado no centro da célula, como pode ser visualizada na figura (4.1). Para avaliar essa propriedade na face da célula em questão, deve-se utilizar média aritmética dos valores vizinhos mais próximos, ou seja

$$
\rho_{i+\frac{1}{2}, j}=\frac{\rho_{i+1, j}+\rho_{i, j}}{2}
$$

onde os valores de $\rho_{i+1, j}$ e $\rho_{i, j}$ estão posicionados nos centros das células adjacentes ao ponto $\left(i+\frac{1}{2}, j\right)$.

Dessa forma, a aproximação fica

$$
\left.\frac{1}{\rho} \frac{\partial p}{\partial x}\right|_{i+\frac{1}{2}, j}=\frac{2\left(p_{i+1, j}-p_{i, j}\right)}{\delta x\left(\rho_{i+1, j}+\rho_{i, j}\right)}
$$

\section{- Discretização do termo viscoso $V i s c_{1}(u)$}

A aproximação do termo viscoso $V i s c_{1}(u)$ é feita por diferenças centrais de segunda ordem, ou seja

$$
\begin{aligned}
\left.\operatorname{Visc}_{1}(u)\right|_{i+\frac{1}{2}, j}= & \frac{\mu_{i+\frac{1}{2}, j}}{\rho_{i+\frac{1}{2}, j} R e}\left[\frac{u_{i-\frac{1}{2}, j}-2 u_{i+\frac{1}{2}, j}+u_{i+\frac{3}{2}, j}}{\delta x^{2}}+\right. \\
& \left.+\frac{u_{i+\frac{1}{2}, j-1}-2 u_{i+\frac{1}{2}, j}+u_{i+\frac{1}{2}, j+1}}{\delta y^{2}}\right] .
\end{aligned}
$$

Novamente, tem-se que aproximar o valor de $\rho_{i+\frac{1}{2}, j}$ por média aritmética dos valores vizinhos mais próximos. Dessa forma, basta tomar a proximação obtida em (4.5). 
A mesma estratégia sugere que se use também uma média aritmética para calcular $\mu_{i+\frac{1}{2}, j}$. Porém, como viscosidades mais baixas dominam a distribuição de forças no escoamento, média aritmética pode não representar bem a natureza física da viscosidade. Pode-se, ao invés disto, utilizar média harmônica entre os valores conhecidos de $\mu$, ou seja,

$$
\mu_{i+\frac{1}{2}, j}=2\left(\frac{1}{\mu_{i+1, j}}+\frac{1}{\mu_{i, j}}\right)^{-1}
$$

Portanto, a aproximação de (4.7), fica

$$
\begin{aligned}
\left.V i s c_{1}(u)\right|_{i+\frac{1}{2}, j}= & \frac{4}{\operatorname{Re}\left(\frac{1}{\mu_{i+1, j}}+\frac{1}{\mu_{i, j}}\right)\left(\rho_{i+1, j}+\rho_{i, j}\right)}\left[\frac{u_{i-\frac{1}{2}, j}-2 u_{i+\frac{1}{2}, j}+u_{i+\frac{3}{2}, j}}{\delta x^{2}}+\right. \\
& \left.+\frac{u_{i+\frac{1}{2}, j-1}-2 u_{i+\frac{1}{2}, j}+u_{i+\frac{1}{2}, j+1}}{\delta y^{2}}\right]
\end{aligned}
$$

- Discretização do termo viscoso $V i s c_{2}(u)$

Para discretizar o termo viscoso $\mathrm{Visc}_{2}(u)$, considere as seguintes aproximações:

$$
\begin{aligned}
& \left.\frac{\partial u}{\partial x}\right|_{i+\frac{1}{2}, j}=\frac{u_{i+\frac{3}{2}, j}-u_{i-\frac{1}{2}, j}}{2 \delta x} ; \\
& \left.\frac{\partial u}{\partial y}\right|_{i+\frac{1}{2}, j}=\frac{u_{i+\frac{1}{2}, j+1}-u_{i+\frac{1}{2}, j-1}}{2 \delta y} ; \\
& \left.\frac{\partial v}{\partial x}\right|_{i+\frac{1}{2}, j}=\frac{v_{i+1, j}-v_{i, j}}{\delta x} .
\end{aligned}
$$

Observe que há pontos da célula onde não são conhecidos os valores das velocidades, ou seja, $v_{i, j}$ e $v_{i+1, j}$ estão no centro das células e, portanto, devem ser aproximados por médias aritméticas dos valores conhecidos de velocidades vizinhas, ou seja,

$$
\begin{aligned}
v_{i, j} & =\frac{v_{i, j+\frac{1}{2}}+v_{i, j-\frac{1}{2}}}{2} ; \\
v_{i+1, j} & =\frac{v_{i+1, j+\frac{1}{2}}+v_{i+1, j-\frac{1}{2}}}{2} .
\end{aligned}
$$


Aproximando os termos,

$$
\begin{aligned}
& \left.\frac{\partial \mu}{\partial x}\right|_{i+\frac{1}{2}, j}=\frac{\mu_{i+1, j}-\mu_{i, j}}{\delta x} ; \\
& \left.\frac{\partial \mu}{\partial y}\right|_{i+\frac{1}{2}, j}=\frac{\mu_{i+\frac{1}{2}, j+\frac{1}{2}}-\mu_{i+\frac{1}{2}, j-\frac{1}{2}}}{\delta y} .
\end{aligned}
$$

note que há pontos da célula onde não são conhecidos os valores das viscosidades. Desta forma, devemos fazer duas aproximações por média harmônica, ou seja

$$
\begin{aligned}
& \mu_{i+\frac{1}{2}, j+\frac{1}{2}}=4\left(\frac{1}{\mu_{i, j+1}}+\frac{1}{\mu_{i+1, j+1}}+\frac{1}{\mu_{i, j}}+\frac{1}{\mu_{i+1, j}}\right)^{-1} \\
& \mu_{i+\frac{1}{2}, j-\frac{1}{2}}=4\left(\frac{1}{\mu_{i, j}}+\frac{1}{\mu_{i+1, j}}+\frac{1}{\mu_{i, j-1}}+\frac{1}{\mu_{i+1, j-1}}\right)^{-1} .
\end{aligned}
$$

Por fim, a discretização de $V i s c_{2}(u)$ fica

$$
\begin{aligned}
& \left.\operatorname{Visc}_{2}(u)\right|_{i+\frac{1}{2}, j}=\frac{1}{\operatorname{Re}\left(\rho_{i+1, j}+\rho_{i, j}\right)}\left\{\frac{\left(\mu_{i+1, j}-\mu_{i, j}\right)\left(u_{i+\frac{3}{2}, j}-u_{i-\frac{1}{2}, j}\right)}{\delta x^{2}}+\right. \\
& \frac{4}{\delta y}\left[\left(\frac{1}{\mu_{i, j+1}}+\frac{1}{\mu_{i+1, j+1}}+\frac{1}{\mu_{i, j}}+\frac{1}{\mu_{i+1, j}}\right)^{-1}-\left(\frac{1}{\mu_{i, j}}+\frac{1}{\mu_{i+1, j}}+\frac{1}{\mu_{i, j-1}}+\right.\right. \\
& \left.\left.\left.\frac{1}{\mu_{i+1, j-1}}\right)^{-1}\right] \cdot\left(\frac{v_{i+1, j+\frac{1}{2}}+v_{i+1, j-\frac{1}{2}}-v_{i, j+\frac{1}{2}}-v_{i, j-\frac{1}{2}}}{2 \delta x}+\frac{u_{i+\frac{1}{2}, j+1}-u_{i+\frac{1}{2}, j-1}}{2 \delta y}\right)\right\} .
\end{aligned}
$$

\section{- Discretização do termo convectivo $\operatorname{Conv}(u)$}

Termos não lineares, tais como os termos convectivos $\operatorname{Conv}(\mathrm{u})$ e Conv(v), presentes na equação de conservação de momento, requerem atenção especial na forma como serão aproximados. A procura de esquemas que asseguram estabilidade nas soluções de equações onde aparecem termos não lineares tem sido assunto de intensa pesquisa.

Embora alguns esquemas de aproximações assegurem a estabilidade numérica, pode ainda haver a introdução de viscosidade artificial predominando sobre a viscosidade real do fluido e, consequentemente, a solução numérica terá um comportamento viscoso mais acentuado do que o da solução analítica. Na tentativa de se elimininar esta viscosidade artificial, foram propostos alguns esquemas, tais como UPWIND de segunda ordem e o QUICK (Quadratic Upstream for Convective Kinematics). Porém estes esquemas produzem oscilações na solução numérica, principalmente em regiões onde se têm gradientes 
elevados.

Experimentos numéricos realizados por Ferreira et. al [7] mostram que esquemas, tais como Diferença Central-CD (Central Difference) e QUICK, são oscilatórios e instavéis em simulações de escoamentos com número de Reynolds elevado (acima de $R e=50$ ). O esquema FOU (First Order Upwind) é robusto, porém produz efeitos de difusão numérica não desejáveis (acima de $R e=500$ ). Por outro lado, o esquema HLPA (Hybrid Linear Parabolic Approximation) mostrou-se robusto e resultou em bons resultados numéricos estavéis na simulação de escoamento de fluido com o número de Reynolds da ordem de 2000 .

Um outro esquema que tem se mostrado bastante robusto e não introduz difusão muito acentuada na solução numérica, e que por este motivo, tem sido utilizado no simulador do ambiente FreeFlow, é o esquema Upwind de alta ordem VONOS (Variable Order Non-Ocilatory Scheme). Experimentos numéricos mostram que este esquema também tem sido capaz de simular escoamentos com números de Reynolds bastante elevados.

Portanto, segue a descrição de dois destes esquemas de aproximações dos termos convectivos Conv( $\mathrm{u})$ e Conv(v), que foram escolhidos para serem implementados neste trabalho: o Diferenças Centrais, por se tratar do esquema originalmente utilizado para aproximações destes termos no FreeFlow, e VONOS, em função deste ter sido inicialmente implementado para o caso tridimensional no sistema FreeFlow com bons resultados apresentados.

\section{- Aproximação por Diferença Central (CD):}

Seja o termo convectivo da equação de conservação de momento na direção $x$, dado pela expressão $(4.2)$

$$
\operatorname{Conv}(u)=\frac{\partial u^{2}}{\partial x}+\frac{\partial(v u)}{\partial y}
$$

Aproximando, primeiramente, o termo $\frac{\partial u^{2}}{\partial x}$ de (4.2) no ponto $\left(i+\frac{1}{2}, j\right)$, tem-se

$$
\left.\frac{\partial u^{2}}{\partial x}\right|_{i+\frac{1}{2}, j}=\frac{(\bar{u} u)_{i+1, j}-(\bar{u} u)_{i, j}}{\delta x} .
$$

onde $\bar{u}_{i+1, j}$ e $\bar{u}_{i, j}$ são as velocidades de transporte, respectivamente aproximadas por médias aritméticas dos valores de velocidade mais próximas, ou seja, 


$$
\bar{u}_{i+1, j}=\frac{1}{2}\left(u_{i+\frac{3}{2}, j}+u_{i+\frac{1}{2}, j}\right) \quad \bar{u}_{i, j}=\frac{1}{2}\left(u_{i+\frac{1}{2}, j}+u_{i-\frac{1}{2}, j}\right) \cdot
$$

Pelo esquema de diferenças centrais, as aproximações das velocidades transportadas $u_{i+1, j}$ e $u_{i, j}$, respectivamente, são

$$
\begin{gathered}
u_{i+1, j}=\left(u_{i+\frac{3}{2}, j}+u_{i+\frac{1}{2}, j}\right) / 2 ; \\
u_{i, j}=\left(u_{i+\frac{1}{2}, j}+u_{i-\frac{1}{2}, j}\right) / 2 .
\end{gathered}
$$

Então,

$$
\left.\frac{\partial u^{2}}{\partial x}\right|_{i+\frac{1}{2}, j}=\frac{u_{i+\frac{3}{2}, j} \cdot u_{i+\frac{1}{2}, j}-u_{i+\frac{1}{2}, j} \cdot u_{i-\frac{1}{2}, j}}{\delta x} .
$$

Em seguida, aproximando o termo $\frac{\partial(v u)}{\partial y}$ de $(4.2)$ no ponto $\left(i+\frac{1}{2}, j\right)$, tem-se

$$
\left.\frac{\partial(v u)}{\partial y}\right|_{i+\frac{1}{2}, j}=\frac{(\bar{v} u)_{i+\frac{1}{2}, j+\frac{1}{2}}-(\bar{v} u)_{i+\frac{1}{2}, j-\frac{1}{2}}}{\delta y}
$$

onde $\bar{v}_{i+\frac{1}{2}, j+\frac{1}{2}}$ e $\bar{v}_{i+\frac{1}{2}, j-\frac{1}{2}}$ são as velocidades de transporte, aproximadas utilizando médias aritméticas, ou seja,

$$
\bar{v}_{i+\frac{1}{2}, j+\frac{1}{2}}=\frac{1}{2}\left(v_{i+1, j+\frac{1}{2}}+v_{i, j+\frac{1}{2}, k}\right) \quad \bar{v}_{i+\frac{1}{2}, j-\frac{1}{2}}=\frac{1}{2}\left(v_{i+1, j-\frac{1}{2}}+v_{i, j-\frac{1}{2}}\right) .
$$

Pelo esquema de diferenças centrais, as velocidade transportadas $u_{i+\frac{1}{2}, j+\frac{1}{2}}$ e $u_{i+\frac{1}{2}, j-\frac{1}{2}}$ são aproximadas pela média aritmética dos pontos $\left(i+\frac{1}{2}, j+\frac{1}{2}\right)$ e $\left(i+\frac{1}{2}, j-\frac{1}{2}\right)$, ou seja

$$
\begin{aligned}
& u_{i+\frac{1}{2}, j+\frac{1}{2}}=\frac{\left(u_{i+\frac{1}{2}, j}+u_{i+\frac{1}{2}, j+1}\right)}{2} ; \\
& u_{i+\frac{1}{2}, j-\frac{1}{2}}=\frac{\left(u_{i, j-\frac{1}{2}}+u_{i+1, j-\frac{1}{2}}\right)}{2} .
\end{aligned}
$$

Então,

$$
\begin{gathered}
\left.\frac{\partial(u v)}{\partial y}\right|_{i+\frac{1}{2}, j}=\frac{1}{4}\left[\frac{\left(u_{i+\frac{1}{2}, j}+u_{i+\frac{1}{2}, j+1}\right) \cdot\left(v_{i, j+\frac{1}{2}}+v_{i+1, j+\frac{1}{2}}\right)}{\delta y}+\right. \\
\left.-\frac{\left(u_{i+\frac{1}{2}, j}+u_{i+\frac{1}{2}, j-1}\right) \cdot\left(v_{i, j-\frac{1}{2}}+v_{i+1, j-\frac{1}{2}}\right)}{\delta y}\right] .
\end{gathered}
$$


Portanto, substituindo as equações (4.10) e (4.11) em (4.2), a aproximação do termo convectivo da equação de momento na direção $x$ é dada por

$$
\begin{gathered}
\operatorname{Conv}(u)=\left(\frac{u_{i+\frac{3}{2}, j} \cdot u_{i+\frac{1}{2}, j}-u_{i+\frac{1}{2}, j} \cdot u_{i-\frac{1}{2}, j}}{\delta x}\right)+ \\
-\frac{1}{4}\left[\frac{\left(u_{i+\frac{1}{2}, j}+u_{i+\frac{1}{2}, j+1}\right) \cdot\left(v_{i, j+\frac{1}{2}}+v_{i+1, j+\frac{1}{2}}\right)}{\delta y}+\right. \\
\left.-\frac{\left(u_{i+\frac{1}{2}, j}+u_{i+\frac{1}{2}, j-1}\right) \cdot\left(v_{i, j-\frac{1}{2}}+v_{i+1, j-\frac{1}{2}}\right)}{\delta y}\right] .
\end{gathered}
$$

- Aproximação pelo Esquema VONOS:

Considere a figura (4.3) abaixo

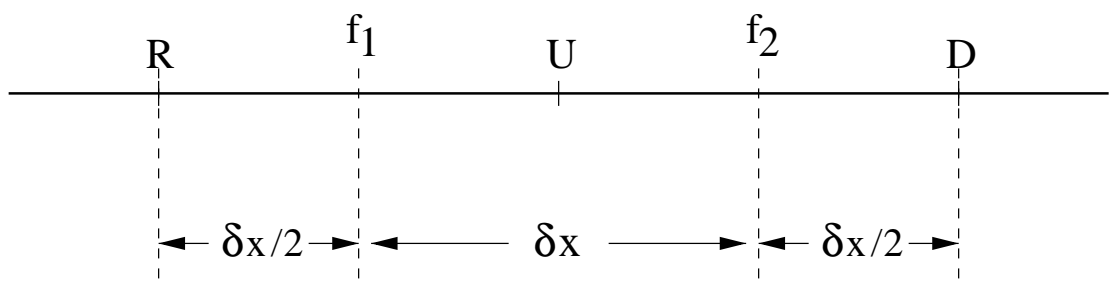

Figura 4.3: Pontos de discretização e faces envolvidas para o esquema de aproximação de termos convectivos

Suponhamos que se queira aproximar a derivada parcial $\frac{\partial \phi}{\partial x}$, onde $\phi$ é uma variável genérica, em uma face $U$, conforme indicado na figura (4.3). Dessa forma, esta derivada é aproximana em $U$ por

$$
\frac{\partial \phi}{\partial x}=\frac{1}{\delta x}\left(\phi_{f_{2}}-\phi_{f_{1}}\right)
$$

onde os termos $\phi_{f_{1}}$ e $\phi_{f_{2}}$ podem ser aproximados, utilizando-se os valores vizinhos da malha, segundo o esquema (4.12) denominado Upwind de Alta Ordem VONOS.

$$
\phi_{f}= \begin{cases}\phi_{U} & \text { se } \hat{\phi}_{U} \notin[0,1], \\ 10 \phi_{U}-9 \phi_{R} & \text { se } 0 \leq \hat{\phi}_{U}<3 / 74, \\ \frac{1}{8}\left(3 \phi_{D}+6 \phi_{U}-\phi_{R}\right) & \text { se } 3 / 74 \leq \hat{\phi}_{U}<1 / 2, \\ 1.5 \phi_{U}-0.5 \phi_{R} & \text { se } 1 / 2 \leq \hat{\phi}_{U}<2 / 3, \\ \phi_{D} & \text { se } 2 / 3 \leq \hat{\phi}_{U} \leq 1 .\end{cases}
$$

onde $\phi_{f}$ é uma variável genérica computada na face $f$ de uma célula. $\hat{\phi}_{U}$ é dado por

$$
\hat{\phi}_{U}=\frac{\phi_{U}-\phi_{R}}{\phi_{D}-\phi_{R}},
$$


onde $\phi_{D}$ é o valor na posição Downstream, $\phi_{U}$ é o valor na posição Upstream e $\phi_{R}$ é o valor na posição Remote-Upstream.

Dessa forma, aproximando-se o termo $\frac{\partial u^{2}}{\partial x}$ da expressão (4.2), tem-se

$$
\begin{aligned}
& \frac{\partial u^{2}}{\partial x}=\frac{(u u)_{i+1, j}-(u u)_{i, j}}{\delta x} \\
= & \frac{1}{\delta x}\left(\bar{u}_{i+1, j} u_{i+1, j}-\bar{u}_{i, j} u_{i, j}\right) .
\end{aligned}
$$

As velocidades de transporte $\bar{u}_{i+1, j}$ e $\bar{u}_{i, j}$ são aproximadas por médias aritméticas, ou seja

$$
\bar{u}_{i+1, j}=\frac{1}{2}\left(u_{i+\frac{3}{2}, j}+u_{i+\frac{1}{2}, j}\right) \quad \bar{u}_{i, j}=\frac{1}{2}\left(u_{i+\frac{1}{2}, j}+u_{i-\frac{1}{2}, j}\right) \cdot
$$

As velocidades transportadas $u_{i+1, j}$ e $u_{i, j}$ são aproximadas utilizando-se os pontos vizinhos conhecidos, de acordo com o sinal das velocidades $\bar{u}_{i+1, j}$ e $\bar{u}_{i, j}$, ou seja,

- Se $\bar{u}_{i+1, j} \geq 0$, então os pontos de aproximação são $D=\left(i+\frac{3}{2}, j\right), U=\left(i+\frac{1}{2}, j\right)$ e $R=\left(i-\frac{1}{2}, j\right)$, figura (4.4).

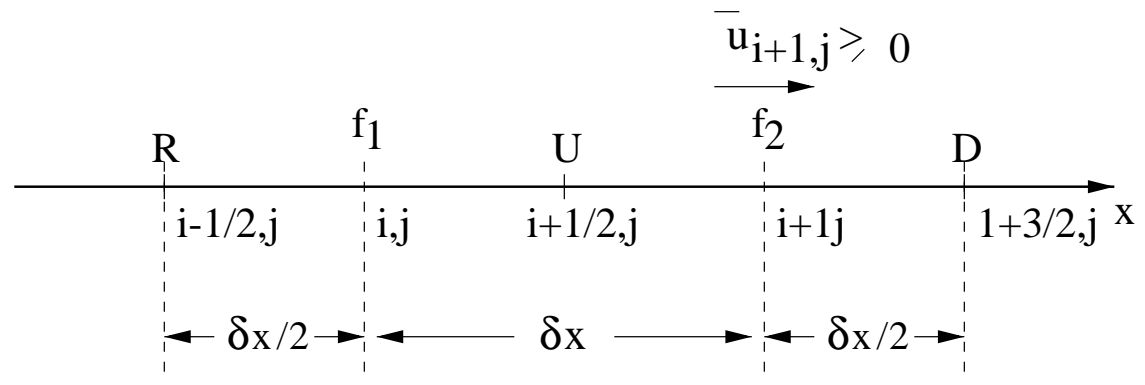

Figura 4.4: Pontos de aproximação da velocidade $u_{i+1, j} \operatorname{com} \bar{u}_{i+1, j} \geq 0$.

- Se $\bar{u}_{i+1, j}<0$, então os pontos de aproximação são $D=\left(i+\frac{1}{2}, j\right), U=\left(i+\frac{3}{2}, j\right)$ e $R=\left(i+\frac{5}{2}, j\right)$, figura $(4.5)$.

- Se $\bar{u}_{i, j} \geq 0$, então os pontos de aproximação são $D=\left(i+\frac{1}{2}, j\right), U=\left(i-\frac{1}{2}, j\right)$ e $R=\left(i-\frac{3}{2}, j\right)$, figura (4.6).

- Se $\bar{u}_{i, j}<0$, então os pontos de aproximação são $D=\left(i-\frac{1}{2}, j\right), U=\left(i+\frac{1}{2}, j\right)$ e $R=\left(i+\frac{5}{2}, j\right)$, figura $(4.7)$.

Da mesma forma, aproximando-se o termo $\left.\frac{\partial(u v)}{\partial y}\right|_{i+\frac{1}{2}, j}$ da expressão (4.2), tem-se

$$
\begin{aligned}
\left.\frac{\partial(u v)}{\partial y}\right|_{i+\frac{1}{2}, j} & =\frac{(u v)_{i+\frac{1}{2}, j+\frac{1}{2}}-(u v)_{i+\frac{1}{2}, j-\frac{1}{2}}}{\delta y} \\
& =\left(\bar{v}_{i+\frac{1}{2}, j+\frac{1}{2}} u_{i+\frac{1}{2}, j+\frac{1}{2}}-\bar{v}_{i+\frac{1}{2}, j-\frac{1}{2}} u_{i+\frac{1}{2}, j-\frac{1}{2}}\right) / \delta y
\end{aligned}
$$




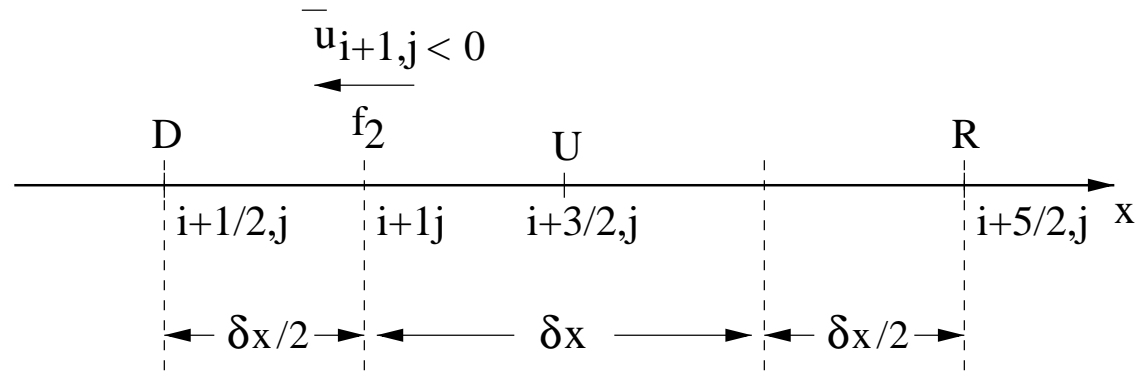

Figura 4.5: Pontos de aproximação da velocidade $u_{i+1, j} \operatorname{com} \bar{u}_{i+1, j}<0$.

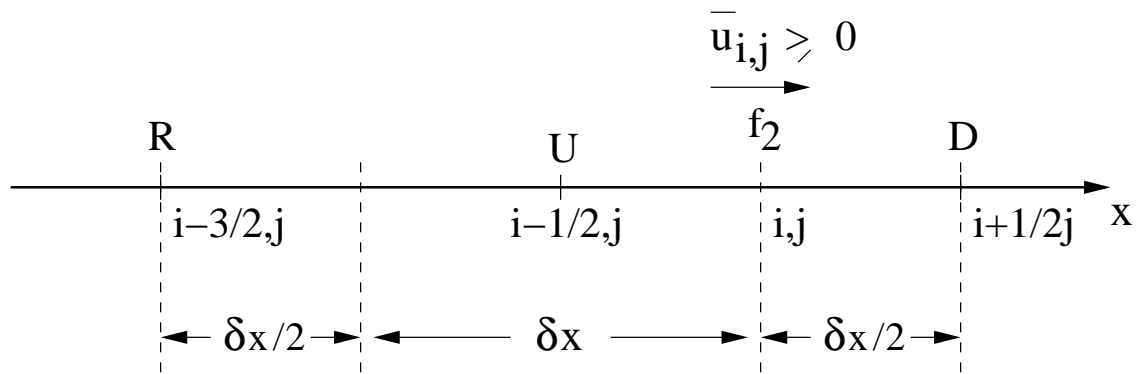

Figura 4.6: Pontos de aproximação da velocidade $u_{i, j} \operatorname{com} \bar{u}_{i, j} \geq 0$.

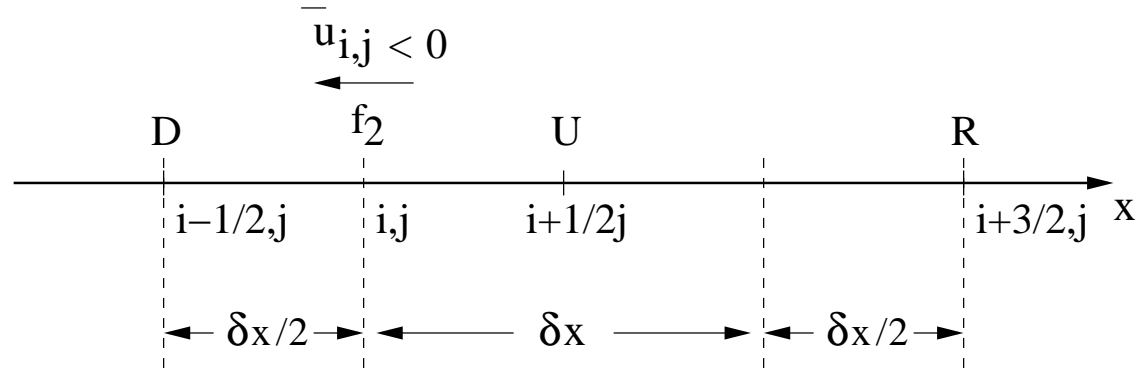

Figura 4.7: Pontos de aproximação da velocidade $u_{i+1, j} \operatorname{com} \bar{u}_{i, j}<0$.

onde as velocidades de transporte $\bar{v}_{i+\frac{1}{2}, j+\frac{1}{2}}$ e $\bar{v}_{i+\frac{1}{2}, j-\frac{1}{2}}$ são aproximadas por médias aritméticas, ou seja,

$$
\tilde{v}_{i+\frac{1}{2}, j+\frac{1}{2}}=\frac{\left(v_{i+1, j+\frac{1}{2}}+v_{i, j+\frac{1}{2}}\right)}{2}, \quad \tilde{v}_{i+\frac{1}{2}, j-\frac{1}{2}}=\frac{\left(v_{i+1, j-\frac{1}{2}}+v_{i, j-\frac{1}{2}}\right)}{2}
$$

e as velocidades transportadas $u_{i+\frac{1}{2}, j+\frac{1}{2}}$ e $u_{i+\frac{1}{2}, j-\frac{1}{2}}$ são aproximadas utilizando-se os pontos vizinhos conhecidos, considerando-se o sinal de $\bar{v}_{i+\frac{1}{2}, j+\frac{1}{2}}$ e $\bar{v}_{i+\frac{1}{2}, j-\frac{1}{2}}$, respectivamente, ou seja

- Se $\bar{v}_{i+\frac{1}{2}, j+\frac{1}{2}} \geq 0$, então os pontos de aproximação são $D=\left(i+\frac{1}{2}, j+1\right), U=\left(i+\frac{1}{2}, j\right)$ e $R=\left(i+\frac{1}{2}, j-1\right)$. 
- Se $\bar{v}_{i+\frac{1}{2}, j+\frac{1}{2}}<0$, então $D=\left(i+\frac{1}{2}, j\right), U=\left(i+\frac{1}{2}, j+1\right)$ e $R=\left(i+\frac{1}{2}, j+2\right)$.

- Se $\bar{v}_{i+\frac{1}{2}, j-\frac{1}{2}} \geq 0$, então os pontos de aproximação são $D=\left(i+\frac{1}{2}, j\right), U=\left(i+\frac{1}{2}, j-1\right)$

e $R=\left(i+\frac{1}{2}, j-2\right)$.

- Se $\bar{v}_{i+\frac{1}{2}, j-\frac{1}{2}}<0$, então $D=\left(i+\frac{1}{2}, j-1\right), U=\left(i+\frac{1}{2}, j\right)$ e $R=\left(i+\frac{1}{2}, j+1\right)$.

Emprega-se o mesmo procedimento para aproximar-se os outros termos da equação de conservação na direção $\left.y \frac{\partial(v v)}{\partial y}\right|_{i, j+\frac{1}{2}}$ e $\left.\frac{\partial(v u)}{\partial y}\right|_{i, j+\frac{1}{2}}$. Os termos $V i s c_{1}(v)$ e $V i s c_{2}(v)$ da equação de momento na direção $y$, são também aproximados da mesma forma como foi feito em $V i s c_{1}(u)$ e $V i s c_{2}(u)$, nesta mesma seção.

Com isto, completa-se a discretização da equação de conservação de momento (2.35).

\subsection{Discretização da Equação Elíptica para $\psi$}

A equação (3.5), utilizada para o cálculo da função potencial $\psi$, é dada por

$$
\nabla \cdot \frac{1}{\rho} \nabla \psi=\nabla \cdot \tilde{u}
$$

cuja representação em coordenadas cartesianas, é dada por

$$
\frac{\partial}{\partial x}\left(\frac{1}{\rho} \frac{\partial \psi}{\partial x}\right)+\frac{\partial}{\partial y}\left(\frac{1}{\rho} \frac{\partial \psi}{\partial y}\right)=\frac{\partial \tilde{u}}{\partial x}+\frac{\partial \tilde{v}}{\partial y}
$$

Aproximando o termo $\frac{\partial}{\partial x}\left(\frac{1}{\rho} \frac{\partial \psi}{\partial x}\right)$ por diferenças centrais, obtém-se:

$$
\left.\frac{\partial}{\partial x}\left(\frac{1}{\rho} \frac{\partial \psi}{\partial x}\right)\right|_{i, j}=\frac{\left.\left(\frac{1}{\rho} \frac{\partial \psi}{\partial x}\right)\right|_{i+\frac{1}{2}, j}-\left(\frac{1}{\rho} \frac{\partial \psi}{\partial x}\right)_{i-\frac{1}{2}, j}}{\delta x}
$$

onde

$$
\begin{aligned}
& \left.\left(\frac{1}{\rho} \frac{\partial \psi}{\partial x}\right)\right|_{i+\frac{1}{2}, j}=\frac{1}{\rho_{i+\frac{1}{2}, j}}\left(\frac{\psi_{i+1, j}-\psi_{i, j}}{\delta x}\right) \\
& \left.\left(\frac{1}{\rho} \frac{\partial \psi}{\partial x}\right)\right|_{i-\frac{1}{2}, j}=\frac{1}{\rho_{i-\frac{1}{2}, j}}\left(\frac{\psi_{i, j}-\psi_{i-1, j}}{\delta x}\right) .
\end{aligned}
$$


Então,

$$
\left.\frac{\partial}{\partial x}\left(\frac{1}{\rho} \frac{\partial \psi}{\partial x}\right)\right|_{i, j}=\frac{1}{\delta x^{2}}\left[\frac{1}{\rho_{i+\frac{1}{2}, j}}\left(\psi_{i+1, j}-\psi_{i, j}\right)-\frac{1}{\rho_{i-\frac{1}{2}, j}}\left(\psi_{i, j}-\psi_{i-1, j}\right)\right] .
$$

De modo análogo para o termo $\frac{\partial}{\partial y}\left(\frac{1}{\rho} \frac{\partial \psi}{\partial y}\right)_{i, j}$, obtém-se:

$$
\left.\frac{\partial}{\partial y}\left(\frac{1}{\rho} \frac{\partial \psi}{\partial y}\right)\right|_{i, j}=\frac{1}{\delta y^{2}}\left[\frac{1}{\rho_{i, j+\frac{1}{2}}}\left(\psi_{i, j+1}-\psi_{i, j}\right)-\frac{1}{\rho_{i, j-\frac{1}{2}}}\left(\psi_{i, j}-\psi_{i, j-1}\right)\right]
$$

e utilizando-se as aproximações de $\rho$ pelas médias dos valores dos pontos vizinhos conhecidos, obtém-se

$$
\begin{gathered}
\left.\frac{\partial}{\partial x}\left(\frac{1}{\rho} \frac{\partial \psi}{\partial x}\right)\right|_{i, j}=\frac{2}{\delta x^{2}}\left[\frac{\psi_{i+1, j}-\psi_{i, j}}{\rho_{i+1, j}+\rho_{i, j}}-\frac{\psi_{i, j}-\psi_{i-1, j}}{\rho_{i, j}+\rho_{i-1, j}}\right] \\
\left.\frac{\partial}{\partial y}\left(\frac{1}{\rho} \frac{\partial \psi}{\partial y}\right)\right|_{i, j}=\frac{2}{\delta y^{2}}\left[\frac{\psi_{i, j+1}-\psi_{i, j}}{\rho_{i, j+1}+\rho_{i, j}}-\frac{\psi_{i, j}-\psi_{i, j-1}}{\rho_{i, j}+\rho_{i, j-1}}\right] .
\end{gathered}
$$

Portanto, o lado direito da equação (4.13) discretizado, se torna

$$
\begin{aligned}
& \frac{1}{\rho_{i+1, j}+\rho_{i, j}} \psi_{i+1, j}+\frac{\alpha}{\rho_{i, j+1}+\rho_{i, j}} \psi_{i, j+1}- \\
& \left(\frac{1}{\rho_{i+1, j}+\rho_{i, j}}+\frac{1}{\rho_{i, j}+\rho_{i-1, j}}+\frac{\alpha}{\rho_{i, j+1}+\rho_{i, j}}+\frac{\alpha}{\rho_{i, j}+\rho_{i, j-1}}\right) \psi_{i, j}+ \\
& \frac{1}{\rho_{i, j}+\rho_{i-1, j}} \psi_{i-1, j}+\frac{\alpha}{\rho_{i, j}+\rho_{i, j-1}} \psi_{i, j-1}=\tilde{D}_{i, j},
\end{aligned}
$$

onde $\alpha=\frac{\delta x^{2}}{\delta y^{2}}$ e $\tilde{D}_{i, j}=\left(\frac{\tilde{u}_{i+\frac{1}{2}, j}-\tilde{u}_{i-\frac{1}{2}, j}}{\delta x}\right)+\left(\frac{\tilde{v}_{i, j+\frac{1}{2}}-\tilde{v}_{i, j-\frac{1}{2}}}{\delta y}\right)$, por diferenças centrais.

\subsubsection{Solução da Equação Elíptica para $\psi$}

A equação discretizada (4.19) gera o sistema linear

$$
A X=D
$$

onde A é uma matriz simétrica esparsa e definida positiva de ordem $n, X$ é um vetor solução de ordem $n$ e $D$ é o vetor divergente $(\nabla \cdot \tilde{u})$ de ordem $n$, onde $n$ representa o 
número de células $\mathrm{F}$ na malha. O método dos gradientes conjugados é utilizado para resolver este sistema linear.

A matriz A é montada aplicando-se a equação (4.19) para cada célula F, linha por linha da direita para a esquerda. Cada célula F corresponde a uma linha de coeficientes da matriz A e a um elemento em D.

A condição homogênea de Neumann modifica os termos da diagonal correspondendo as células F com lados em comum com a fronteira virtual. A condição homogênea de Dirichlet na superfície livre é aplicada passando-se o elemento fora da diagonal nas linhas correspondentes as células F, que tem os lados em comum com as células S, para o lado direito da equação (vetor $D$ ).

Após a montagem da matriz $\mathrm{A}$ e do vetor $\mathrm{D}, \mathrm{X}$ é inicializado como um vetor da função potencial do passo no tempo anterior e aplicamos o método de Gradientes Conjugados sobre o sistema (4.20). Neste ponto, pode-se empregar um precondicionador que acelera a convergência do método dos gradientes conjugados.

\subsection{Procedimento de Aproximação da Interface e de Distribuição da Tensão Interfacial}

Considere a força interfacial presente na equação de conservação de momento (2.17), dada por

$$
\mathbf{f}=\sigma_{I} \kappa \delta\left(x-x^{f}\right) \mathbf{n}
$$

Para introduzir os efeitos da tensão interfacial, é preciso determinar a contribuição desta força $\mathbf{f}$ que será aplicada ao longo da interface, no domínio discreto.

Considerando uma malha com o espaçamento suficientemente pequeno, aproxima-se a interface pelas faces das células adjacentes, e em seguida, avalia-se a porção da força a ser distribuída em cada uma das faces das células utilizadas para aproximação da interface.

Considere uma célula $(i, j)$ da interface com dimensões $(\delta x, \delta y)$. Integrando a equação de conservação de momento (2.35) na área definida pela célula interface, obtém-se a contribuição da tensão superficial nesta célula.

Seja $F_{i, j}$ a força obtida pela integração de (2.35) e $A$ a área da célula interface. Assim, 
temos

$$
\mathbf{F}_{i, j}=\frac{1}{\delta x \delta y} \iint_{A} \frac{\sigma_{I} \kappa}{W e} \delta(s) \mathbf{n} d A .
$$

Pela propriedade da função delta de Dirac, tem-se

$$
\iint_{A} \frac{\sigma_{I} \kappa}{W e} \delta(s) \mathbf{n} d A=\int_{C} \frac{\sigma_{I} \kappa}{W e} \mathbf{n} d C
$$

onde $C$ é a curva definida pela interface dos fluidos, ou seja, a integral de área se torna uma integral no comprimento da curva definida pela interface.

Como a interface é aproximada em cada face de uma célula interface, vale destacar que a interface terá, então, a espessura de pelo menos uma célula do domínio discretizado. Portanto, a curva (C) da interface é aproximada por duas outras curvas, dadas pelas faces da célula interface que esteja em contato com células $\mathrm{F}$ de outras fases.

Dessa forma, tem-se que existe um vetor normal distinto para cada uma das faces. Chamando de $\mathbf{n}_{f}$ este vetor normal, tem-se que $\frac{\sigma_{I} \kappa}{W e} \mathbf{n}_{f}$ será constante em cada face da célula de aproximação da curva $\left(C_{f}\right)$. Logo,

$$
\begin{aligned}
\mathbf{F}_{i, j} & =\sum_{f} \frac{1}{\delta x \delta y} \int_{C_{f}} \frac{\sigma_{I} \kappa}{W e} \mathbf{n}_{f} d C_{f} \\
& =\sum_{f} \frac{\sigma_{I} \kappa}{\delta x \delta y W e} \mathbf{n}_{f} \int_{C_{f}} d C_{f} \\
& =\sum_{f} \frac{\sigma_{I} \kappa}{\delta x \delta y W e} \Delta_{C_{f}} \mathbf{n}_{f},
\end{aligned}
$$

onde $\sum_{f}$ é o somatório das faces da células de aproximação e $\Delta_{C_{f}}$ é o comprimento de cada face utilizada para aproximar a interface da célula $(i, j)$.

Dessa forma, a questão de determinar a contribuição da força $\mathbf{F}_{i, j}$ para cada face utilizada para aproximar a interface depende do vetor normal e do comprimento desta face.

Se uma célula é, portanto, suficientemente pequena de forma que a interface seja aproximada pela face desta célula, então tem-se os seguintes casos:

(a) Célula interface com duas faces opostas adjacentes à células $\mathrm{F}$ de cada fase.

Logo, para este caso, $\mathbf{n}=(1,0)$ e o comprimento é $\Delta_{C}=\delta y$. Dessa forma, substituindo em (4.24), obtém-se

$$
\begin{aligned}
& \left(F_{x}\right)_{i, j}= \pm \frac{\sigma_{I} \kappa \Delta_{C}}{\delta x \delta y W e}= \pm \frac{\sigma_{I} \kappa}{\delta x W e} \\
& \left(F_{y}\right)_{i, j}=0
\end{aligned}
$$


Tem-se nesta célula portanto somente a contribuição da componente $x$ da força $F_{i, j}$, da qual metade do valor será aplicada em cada uma das faces de aproximação da interface, como ilustra a figura (4.8).

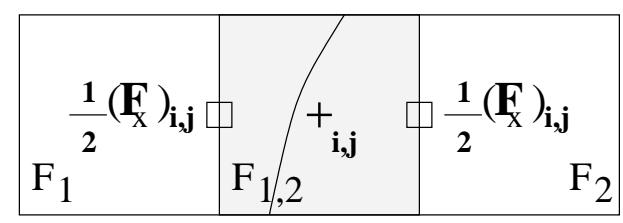

Figura 4.8: Célula interface com lados esquerdo e direito adjacentes à células F de cada fase

Outros tipos de células interface com duas faces adjacentes em contato com células F de cada fase, são tratados de modo análogo.

(b) Célula interface com duas faces adjacentes e não oposta em contato com células $\mathrm{F}$ de cada fase.

Neste caso, tem-se $\mathbf{n}_{1}=(1,0)$ e $\mathbf{n}_{2}=(0,1)$ e os comprimentos de cada face são $\Delta_{C_{1}}=\delta y$ e $\Delta_{C_{2}}=\delta x$. Logo substituindo em (4.24), obtém-se

$$
\mathbf{F}_{i, j}=\sum_{f=1}^{2} \frac{\sigma_{I} \kappa \Delta_{C_{f}}}{\delta x \delta y W e} \mathbf{n}_{f}=\frac{\sigma_{I} \kappa}{\delta x W e} \mathbf{n}_{1}+\frac{\sigma_{I} \kappa}{\delta y W e} \mathbf{n}_{2}
$$

ou seja,

$$
\begin{aligned}
& \left(F_{x}\right)_{i, j}= \pm \frac{\sigma_{I} \kappa}{\delta x W e} \\
& \left(F_{y}\right)_{i, j}= \pm \frac{\sigma_{I} \kappa}{\delta y W e} .
\end{aligned}
$$

Portanto, tem-se a contribuição das duas componentes $x$ e $y$ da força $\left(\mathbf{F}_{i, j}\right)$ e, da mesma forma, distribui-se metade de cada direção para cada face adjacente não oposta à célula F, figura (4.9).

Outros tipos de células interface com faces adjacentes não opostas à células F são tratados analogamente.

(c) Célula interface com três faces adjacentes em contato com células F de cada fase.

Neste caso, a aproximação da interface será feita utilizando-se três faces adjacentes a células F. Portanto, teremos a contribuição das duas componentes $x$ e $y$ da força $\mathbf{F}_{i, j}$ e, 


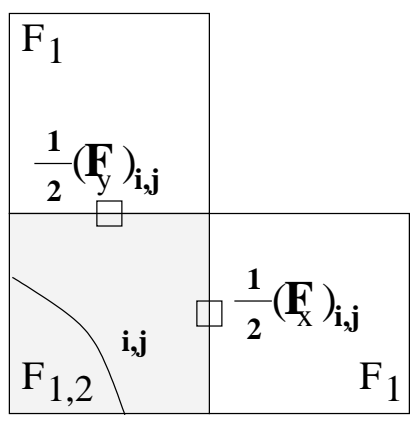

Figura 4.9: Célula interface com lados adjacentes não opostos à células $F$ de cada fase

da mesma forma como nos casos anteriores, seus valores podem ser distribuidos metade em cada face de aproximação da interface, mas com sinal invertido na face da esquerda, já que a orientação da normal desta face é contrária a da face direita, de acordo com a figura (4.10).

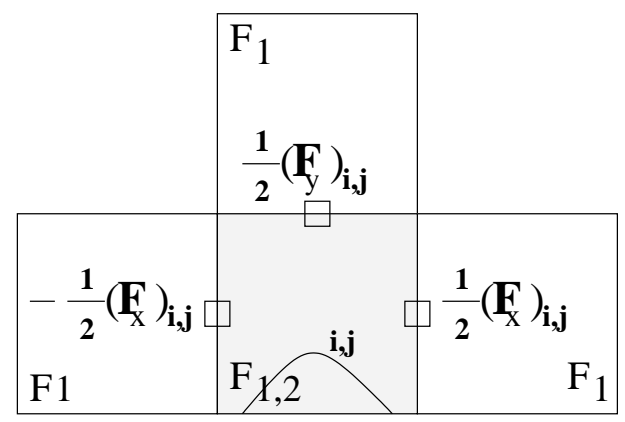

Figura 4.10: Célula interface com três faces adjacentes à células $\mathrm{F}$ 
Uma outra forma de prescrever a distribuição da força $\mathbf{F}$ nas faces de aproximação da célula interface, para este caso, é fazer com que a face oposta à face que recebe a contribuição $\left(F_{y}\right)_{i, j}$, receba a contribuição total da componete $y$ desta força , ilustrada na figura (4.11).

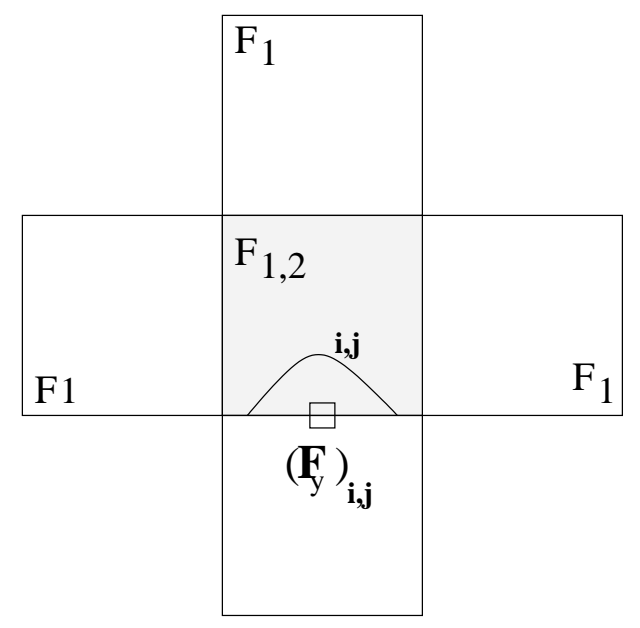

Figura 4.11: Célula interface com três faces adjacentes à células $\mathrm{F}$

De modo análogo, trata-se os outros tipos de células interface com três faces adjacentes às células $\mathrm{F}$.

Em suma, as componentes da força $\mathbf{F}_{i, j}$ são aplicadas nas faces sempre respeitando as adjacências com células F. Além disso, como a interface é aproximada por duas outras curvas, dadas pela faces da célula interface, cada face de aproximação recebe metade do valor da força em cada direção. Por fim, o sinal das contribuições de cada componente da força é escolhido de acordo com a orientação do vetor normal usado no cálculo da curvatura, e a normal da face.

\subsection{Condições de Contorno na Superfície Livre}

As equações de condição de contorno na superfície livre são aproximadas por diferenças finitas locais, considerando-se três tipos de orientação para a superfície livre: horizontal, vertical e superfície inclinada em 45 graus.

Assumindo que as dimensões das células são pequenas o suficiente para que a su- 
perfície intercepte uma célula em dois lados. Então tem-se três casos:

(a) Célula S com apenas um lado em contato com uma célula E:

Para essas células assume-se que a superfície será horizontal ou vertical.

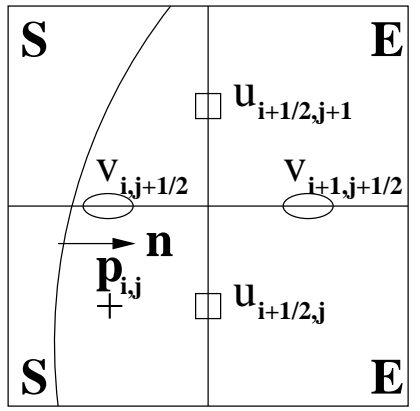

Figura 4.12: Célula S com o lado direito em contato com uma célula E

Logo $\boldsymbol{n}=(1,0)$ e $\boldsymbol{m}=(0,1)$ e substituindo em (2.36) e (2.37), obtém-se:

$$
\begin{gathered}
\frac{\partial u}{\partial y}+\frac{\partial v}{\partial x}=0 \\
-p+\frac{2 \nu}{R e}\left(\frac{\partial u}{\partial x}\right)=\frac{\kappa}{W e}
\end{gathered}
$$

Aproximando por diferenças finitas as equações (4.25) e (4.26), tem-se:

$$
\begin{gathered}
\left(\frac{u_{i+\frac{1}{2}, j+1}-u_{i+\frac{1}{2}, j}}{\delta y}\right)+\left(\frac{v_{i+1, j+\frac{1}{2}}-v_{i, j+\frac{1}{2}}}{\delta x}\right)=0 \\
p_{i, j}=\frac{2 \nu}{R e}\left(\frac{u_{i+\frac{1}{2}, j}-u_{i-\frac{1}{2}, j}}{\delta x}\right)-\frac{\kappa}{W e}
\end{gathered}
$$

Outros tipos de células $\mathrm{S}$ com um lado em comum com a célula E são tratados analogamente.

(b) Células S com dois lados em contato com uma célula E:

Para essas células assume-se que o vetor normal situa-se em $45^{\circ} \mathrm{com}$ os lados em comum com a célula E. Então $\boldsymbol{n}=\left( \pm \frac{\sqrt{2}}{2}, \pm \frac{\sqrt{2}}{2}\right)$ e as condições de contorno (2.36) e (2.37), ficam 


$$
\begin{gathered}
\frac{\partial u}{\partial x}-\frac{\partial v}{\partial y}=0 \\
-p \pm \frac{\nu}{R e}\left(\frac{\partial u}{\partial y}+\frac{\partial v}{\partial x}\right)=\frac{\kappa}{W e}
\end{gathered}
$$

O sinal de (4.28) será o sinal de $n_{x} n_{y}$.

Aproximando-se por diferenças finitas as equações (4.27) e (4.28) tem-se

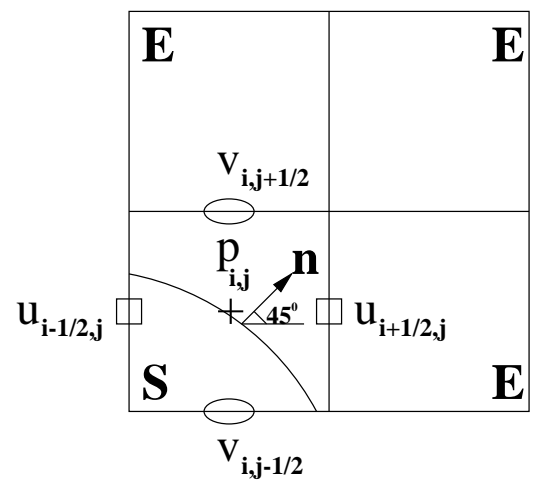

Figura 4.13: Célula S com dois lados em contato com células E

$$
\begin{gathered}
\left(\frac{u_{i+\frac{1}{2}, j}-u_{i-\frac{1}{2}, j}}{\delta x}\right)-\left(\frac{v_{i, j+\frac{1}{2}}-v_{i, j-\frac{1}{2}}}{\delta y}\right)=0 ; \\
p_{i, j}=\frac{\nu}{2 R e}\left[\left(\frac{u_{i+\frac{1}{2}, j}+u_{i-\frac{1}{2}, j}-u_{i+\frac{1}{2}, j-1}-u_{i-\frac{1}{2}, j-1}}{\delta y}\right)\right. \\
\left.+\left(\frac{v_{i, j+\frac{1}{2}}+v_{i, j-\frac{1}{2}}-v_{i-1, j+\frac{1}{2}}-v_{i-1, j-\frac{1}{2}}}{\delta x}\right)\right]-\frac{\kappa}{W e} .
\end{gathered}
$$

Outros tipos de células S com dois lados em comum à célula E são tratados analogamente.

(c) Células S com três lados em contato com células E ou dois lados opostos em contato com células E.

Para estas células a pressão é zero e a velocidade é ajustada a fim de que $\nabla \cdot \mathbf{u}=0$ na célula S. Se tais células aparecerem sugere-se que a malha seja refinada. 


\subsection{Controle do Passo no Tempo}

Um procedimento de controle do passo no tempo é usado para otimizar o tamanho do passo no tempo em cada ciclo de cálculo. Em cada ciclo as rotinas do simulador devem escolher automaticamente o espaçamento no tempo mais apropriado para o cálculo do campo de velocidade, baseado em três restrições de estabilidade como segue:

(a) Nenhuma partícula cruzará mais do que uma célula em um dado intervalo de tempo.

$$
\delta t<\frac{\delta x}{|u|} \quad \text { e } \quad \delta t<\frac{\delta y}{|v|}
$$

Para (4.29) ser satisfeita é suficiente que

$$
\delta t<\frac{\delta x}{\left|U_{\max }\right|} \quad \text { e } \quad \delta t<\frac{\delta y}{\left|V_{\max }\right|}
$$

onde $U_{\text {max }}$ e $V_{\max }$ são os valores máximos de u e v, respectivamente.

(b) A segunda restrição de estabilidade é devida à discretização explícita das equações de momento e envolve o número de Reynolds $(R e)$ e a viscosidade $(\mu)$.

$$
\delta t<\frac{R e}{2 \nu} \frac{\delta x^{2} \delta y^{2}}{\delta x^{2}+\delta y^{2}}
$$

Para (4.30) ser satisfeita é suficiente que

$$
\delta t<\frac{R e}{2 \nu_{\max }} \frac{\delta x^{2} \delta y^{2}}{\delta x^{2}+\delta y^{2}}
$$

onde $\nu_{\max }=\max \left\{\nu_{i, j}\right\}$.

(c) A terceira restrição de estabilidade é devido aos termos de tensão interfacial. No caso de escoamentos dominados com efeitos de tensão interfacial, Sussuman at. al. [22] apresentam uma expressão para a restrição do passo no tempo $(\delta t)$ devida a este termo, dada por

$$
\delta t=\sqrt{\left(\rho_{c}+\rho_{b}\right) B / 4 \pi}
$$

onde $B=4 \rho_{c} g R^{2} / \sigma$ é o número de Bond, $\rho_{c}$ é a densidade de uma fase contínua e $\rho_{b}$ é a densidade de uma bolha (ou gota). 


\section{Capítulo 5}

\section{Ambiente FreeFlow-2D de}

\section{Simulação Numérica}

\subsection{Introdução}

Neste capítulo descreve-se os módulos do ambiente de simulação para escoamentos multifásicos de fluidos incompressível em duas dimensões, para o sistema FreeFlow-2D [14]. A seção seguinte descreve uma síntese de cada módulo deste ambiente de simulação. Em seguida, apresentam-se os módulos de simulação de escoamentos multifásicos, a estrutura de dados. Por fim, a estratégia de reconhecimento de fases.

\subsection{O Ambiente de Simulação FreeFlow-2D}

O FreeFlow-2D é composto pelos seguintes módulos:

- Modelador de Moldes e Escoamentos (Modflow-2D):

Este módulo permite, de forma interativa, definir o domínio do escoamento como moldes, injetores, fluidos e propriedades do fluido.

- Simulador de escoamentos (Simflow-2D):

Neste módulo encontram-se as rotinas de implementação das equações governantes e das condições de fronteira, discretizadas. É considerado a parte central do FreeFlow-2D.

- Visualizador de escoamentos (Visflow-2D):

Sistema interativo que permite a visualização gráfica dos resultados da simulação.

- Reinicializador de escoamentos (Resimflow-2D): 
Sistema com a função de reiniciar a simulação a partir do ponto em que foi interrompida ou quando alguns parâmetros necessitam ser alterados.

\subsection{Módulos do Sistema FreeFlow-2D para Escoa- mento Multifásico}

As principais etapas deste projeto podem ser divididas no desenvolvimento dos módulos do sistema FreeFlow-2D para escoamentos multifásicos. A etapa inicial começou com o desenvolvimento do Modelador, denominado Modflow-2D, para escomentos multifásicos, o que implicou também no desenvolvimento da sua interface gráfica integrada ao sistema FreeFlow-2D. Pararalelo a isto foi desenvolvido o Simulador, Simflow-2D e, por fim, o módulo de visualização do escoamento, Visflow-2D.

\subsubsection{O Modelador Multifásico}

Este módulo permite ao usuário construir e manipular objetos. Tais operações podem ser feitas por meio de uma interface gráfica de fácil execução do Modflow-2D, a qual utiliza o sistema de gerenciamento de janelas Xview sobre o Xwindows. Os objetos geométricos básicos são pré-definidos. O usuário pode escolher, dentre os objetos disponíveis, o seu tamanho, formato, posição e orientação. A interface principal do Modflow-2D possui quatro operações em seu menu: File, Edit, View e View Options.

Ao dar início à construção de um modelo multifásico, o usuário deverá especificar, além de todos os dados que configurarão o escoamento, tais como: domínio, dimensão das células, tempo inicial e final, ciclo inicial e final, escalas de velocidade e comprimento, força gravitacional (intensidade e direção), propriedades do fluido, ou seja, densidade, viscosidade, tensões superficial e interfacial, e principalmente o número de fases a ser considerado na simulação, como pode ser visto na figura (5.1).

Cada fluido determina uma fase no escoamento. Se o usuário deseja simular um escoamento bifásico, então para cada objeto geométrico do tipo fluido, além de seus parâmetros de suas dimensões e posicionamento no domínio, deverá também associar um número de fase ao fluido, como pode ser observado na figura (5.2).

Uma vez especificado o número de fases associado a algum tipo de fluido, pode-se definir suas propriedades e identificá-las por este valor, ou seja, as propriedades de cada 


\begin{tabular}{|l|}
\hline$-D$ MULTI-FLUID FLOW PROPERTIES \\
Name-Fluid : Phase 1 \\
Phase : 1 \\
Viscosity : 0.50000 \\
Density : 1.000 \\
Surface-Tension : 0.010000 \\
Execute \\
Geometry Form : FLUID
\end{tabular}

(a) Entrada das propriedades da fase 1

\begin{tabular}{l}
\hline$--1 \quad$ MULTI-FLUID FLOW PROPERTIES \\
\hline Name-Fluid : Phase2 \\
Phase $: 2$ \\
Viscosity : 0.0050000 \\
Density : $\underline{0.100}$ \\
Surface-Tension : $\underline{0.10000}$ \\
Execute \\
Geometry Form : FLUID
\end{tabular}

(b) Entrada das propriedades da fase 2

Figura 5.3: Entrada das propriedades de cada fase

tratam de inserir fluido no decorrer da simulação, ocasionando o escoamento de fluido por injeção. Estes fluidos expelidos pelos injetores são depositados em recipientes denominados containers. Dessa forma, o usuário poderá simular a injeção de um ou mais fluido em um container. O fluido injetado, também deverá estar associado a um valor de fase. Com isto, pode-se considerar a presença de injetor expelindo um determinado tipo de fluido. Portanto, na janela de entrada de dados para o injetor, foi criado um campo com identicação da fase correspondente ao fluido que o injetor irá expelir, figura (5.4).

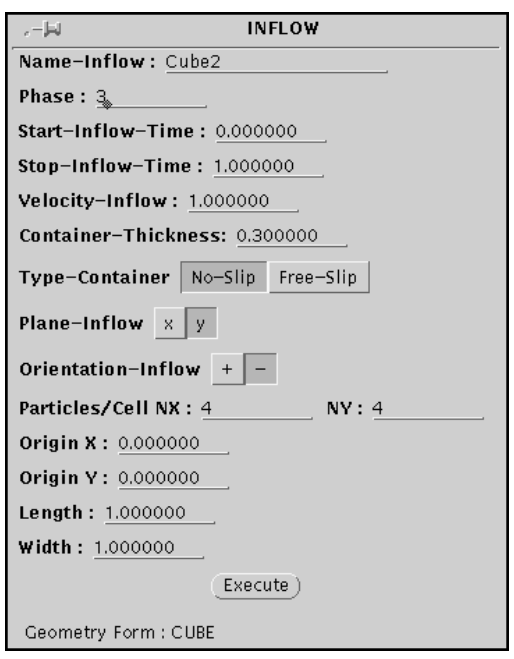

Figura 5.4: Definição de fase no injetor 


\subsubsection{Estratégia de Inclusão de Fases}

Considere um escoamente bifásico, onde se tem uma fase com superfície livre (fase contínua) e uma fase imersa (fase dispersa).

Este modelo poderia ser, por exemplo, uma bolha ou gota (fases dispersas) imersa num fluido (fase contínua). Para se modelar este problema de escoamento multifásico, deve-se seguir a seguinte estratégia de inclusão de fases:

- Considerando-se as dimensões do container previamente configurado e especificando o número de fases como sendo 2, figura (5.1), inclui-se a fase contínua, fluido do tipo Cube, utilizando a janela da figura (5.2) (a). Observe nesta mesma figura que exite um campo de escolha denominado (type), onde as opções são: Fluid ou Hole. A primeira opção de escolha siginifica que aquela fase será um fluido. A segunda opção, significa que naquela fase, no caso a fase contínua, será criado um espaço para a inclusão da fase dispersa. Esta escolha pode ser vista na figura (5.5), e note também a indentificação da fase desta escolha.

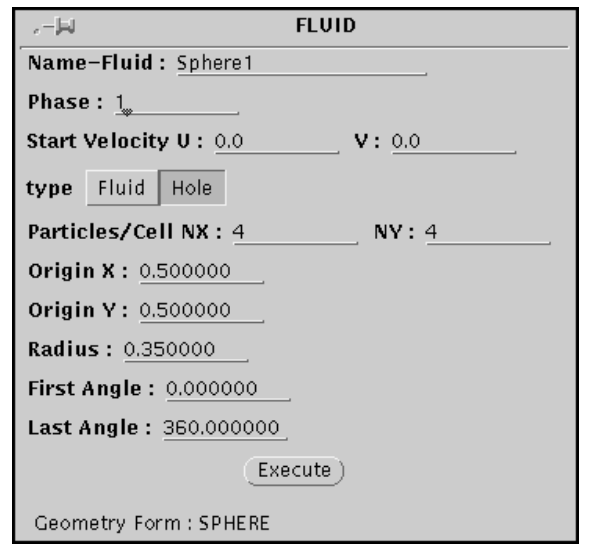

Figura 5.5: Etapa intermediária para a inclusao de fases

- Para incluir a fase dispersa, no caso um fluido esférico (Sphere), deve-se utilizar a janela ilustrada na figura (5.2) (b). Note o número da fase e a opção Fluid escolhida. Esta fase deve ter seu posicionamento direcionado exatamente para o lugar onde se criou o espaço na fase contínua, tomando-se o cuidado para que o raio desta fase não exceda o espaço criado na outra fase. Note na figura (5.6) a configuração das células das fases contínua e dispersa.

Efetuadas estas etapas da modelagem de um problema bifásico, a configuração global das células das fases contínua e dispersa pode ser observada na figura (5.7). Note que, 


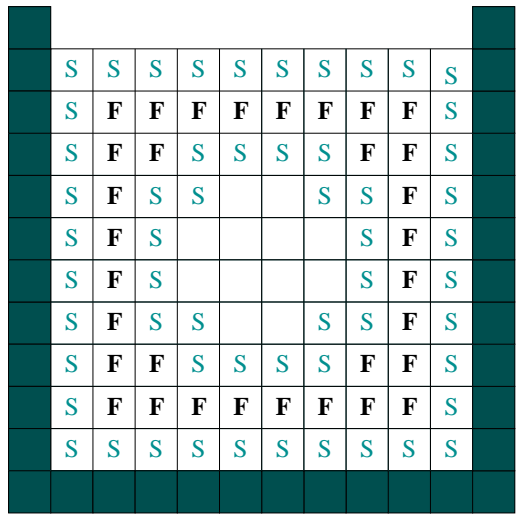

(a) Células da fase contínua

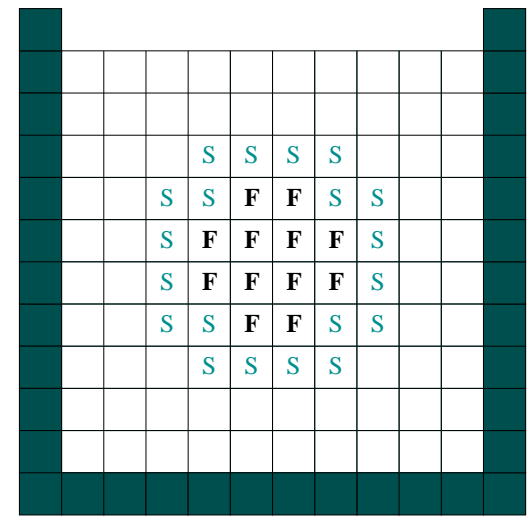

(b) Células da fase dispersa

Figura 5.6: Configuração das células de cada fase separadamente

nesta figura, as células em contato com a fronteira do container e entre as duas fases são células do tipo S. Porém, estas células serão redefinidas, uma vez que não possuem contato com células do tipo E, e portanto serão defininas como F, e somente as $\mathrm{S}$ em contato com a superfície livre é que permanecerão células de superfície.

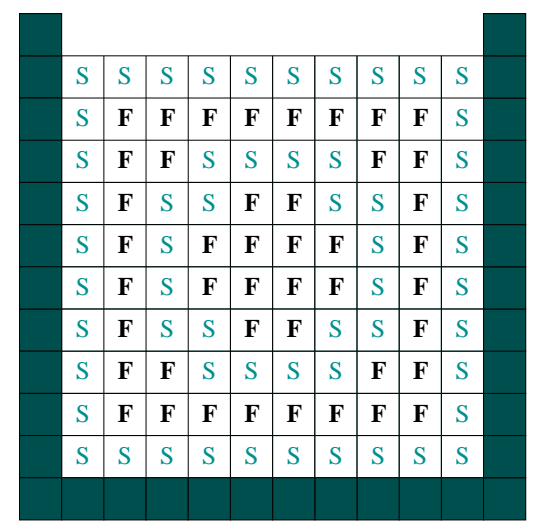

Figura 5.7: Configuração global das células do modelo bifásico

\subsubsection{O Simulador Multifásico}

O módulo Simflow-2D tem a finalidade de simular numericamente escoamentos transientes de fluidos newtonianos incompressíveis considerando-se os efeitos de tensão superficial. No Simflow-2D para escoamentos multifásicos tem-se, ainda, que considerar os efeitos de tensão interfacial, em função da possibilidade de se ter várias fases. Este 
módulo será o único a não possuir uma interface gráfica de entrada de dados. A execução deste módulo se faz seguindo uma sintaxe, efetuada por linha de comando.

Ao se simular um escoamento utilizando o FreeFlow-2D, o Simflow-2D faz uma leitura no arquivo de dados gerado pelo Modelador. Este arquivo de dados armazena todas as informações dos objetos da simulação (Containers, fluidos e suas dimensões), armazena também as propriedades de cada fluido (densidade, viscosidade, tensõessuperficial e interfacial). Por fim, armazena os parâmetros iniciais do escoamento (tempo inicial e final de simulação, dimensões da malha, etc.). Dessa forma, inicia-se um ciclo que vai desde os cálculos do campo de velocidade até a redefinição das células. Este ciclo segue os seguintes passos:

passo 1: Calcula-se o vetor campo de velocidade $\mathbf{u}$

- na superfície livre;

- tangenciais nas células S com as células E;

- no contorno rígido;

- tangenciais nos injetores.

passo 2: Calcula-se o gradiente de pressão $\tilde{p}$ na superfície livre, utilizando-se as condições de contorno.

passo 3: Calcula-se o vetor campo de velocidade intermediária.

passo 4: Resolve-se a equação elíptica para a função potencial $\psi$.

passo 5: Calcula-se o vetor campo de velocidade final (atualizada).

passo 6: Repete-se o passo 1.

passo 7: Calcula-se o vetor campo de velocidade das partículas virtuais (movimento da superfície livre e interface entre as fases).

passo 8: Inserem-se partículas virtuais nos injetores.

passo 9: Eliminam-se partículas virtuais.

passo 10: Inserem-se partículas virtuais.

passo 11: Redefinem-se as células após a inserção das partículas.

Com relação ao passo 1, vale destacar que o Simflow-2D multifásico calcula o campo de velocidade nas células de interface entre os fluidos diretamente das equações de conservação de momento e de massa, percorrendo a árvore de representação destas células e adicinando o termo de tensão interfacial; no contorno rígido calcula-se este campo de velocidade nas faces das células por interpolação linear. 
No passo 2, ao gradiente de pressão é acrescentada a tensão superficial nas células do tipo S. No passo 3, são aplicadas, nas células do tipo F, as equações de conservação de momento e de conservação de massa para escoamentos multifásicos que consideram propriedades variáveis de acordo com posição da interface.

O passo 4 resolve a equação (3.5) para a função potencial $\psi$, pelo método de Gradientes Conjugados, utilizando condições de fronteira adequadas para esta função, supondo ainda um campo de pressão arbitrária satisfazendo a condição de pressão na superfície livre.

O cálculo do vetor campo de velocidade final, passo 5, é obtido por meio de um campo de velocidade intermediária discretizando no tempo a equação elíptica da função potencial $\phi$. Uma vez atualizado o campo de velocidade, é possível obter a nova posição das partículas marcadoras de fluido, passo 7.

Após fazer as operações de inserção e remoção de partículas (passos 8,9 e 10), necessárias para se obter a representação fiel dos detalhes da superfície do fluido, redefinemse as células. Assim, células que contêm a superfície livre são marcadas por ter partículas virtuais. Encerra-se nesta redefinição o ciclo e retorna-se ao passo 1, até que se obtenha a simulação desejada.

\subsubsection{O Visualizador Multifásico}

O módulo de visualização, Visflow-2D, é responsável por apresentar graficamente os resultados gerados pelo Simflow-2D. Este módulo também possui uma interface gráfica para facilitar a sua utilização.

Para facilitar a tradução dos resultados obtidos da simulação, este módulo apresenta imagens gráficas de fácil interpretação. Estas imagens estão baseadas nos objetos geométricos, nas propriedades de cada fluido e nos resultados gerados pelo simulador. Para a visualização dos campos de velocidade e pressão, utiliza-se uma técnica de escala de cores, associada aos valores destes campos. No caso bidimensional a velocidade é visualizada pelas suas duas componentes: a velocidade $u$ na direção $x$ e a velocidade $v$ na direção $y$.

Existe uma comunicação entre os módulos, Modflow-2D, Simflow-2D e Visflow-2D efetuada por meio de arquivos de dados, gerados por rotinas específicas, divididas em duas classes distintas: rotina grava, responsável por armazenar as informações em arquiv- 
os e rotina carrega, responsável por fazer a leitura destes dados gravados. A comunicação destes módulos por meio destas rotinas, pode ser visualizada na figura (5.8).

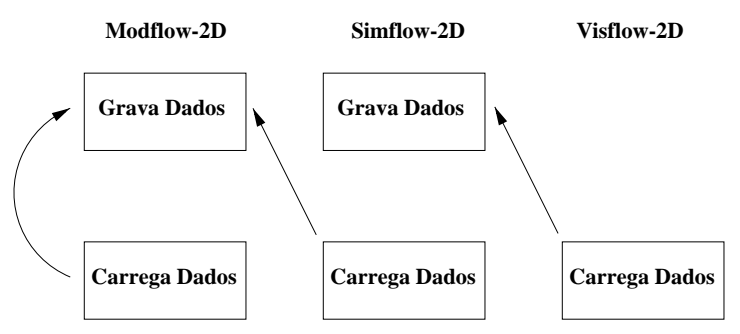

Figura 5.8: Estrutura de comunicação entre os módulos

Dados como densidade, viscosidade, tensões superficial e interfacial são gravados e carregados por estas rotinas em cada módulo, exceto no Visflow-2D, que somente faz a leitura destas propriedades geradas pelas rotina grava dos módulos Modflow-2D e Simflow-2D, para ser efetuada a visualização do escoamento.

$\mathrm{Na}$ implementação destas rotinas de armazenamento e leitura, a disposição dos dados deve ser a mesma para todos os módulos, pois do contrário, a comunicação entre estes módulos pode falhar, e consequêntemente, o sistema não funcionará. Por exemplo, se o módulo for o Modflow-2D o modelo pode não ser carregado. Por outro lado, se o módulo for o Simflow-2D, a simulação não ocorrerá.

\subsubsection{Estrutura de Dados e Estratégias de Reconhecimento de Fases}

Objetos geométricos no FreeFlow-2D são curvas fechadas com orientação anti-horária. Os objetos geométricos são representados pela sua fronteira (Slice, Edge, Vertex e suas relações topológicas) por um tipo de estrutura de dados denominada B-Rep (Bondary Representation). A figura (5.9) ilustra os elementos Slice (S) e Face (F) obtidos com um corte num objeto qualquer.

Para o FreeFlow-2D a estrutura de dados utilizada é denominada halfedge-2D. A estrutura halfedge-2D está dividida em quatro itens: Slice, Face, Edge e Vertex.

\section{- Níveis Hierárquicos da estrutura halfedge-2d}

Os itens Slice, Face, Edge e Vertex são listas duplamente encadeadas, sendo que as listas de edges são ainda circulares. A disposição dos ponteiros para as listas e para um 


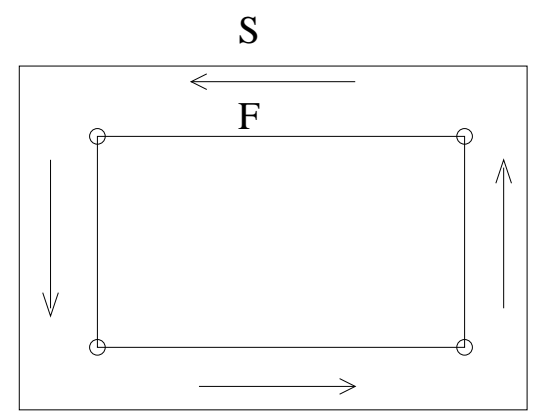

Figura 5.9: Fatia (S) e Face (F) obtidas com um corte num sólido

elemento das listas está mostrada na figura (5.10).

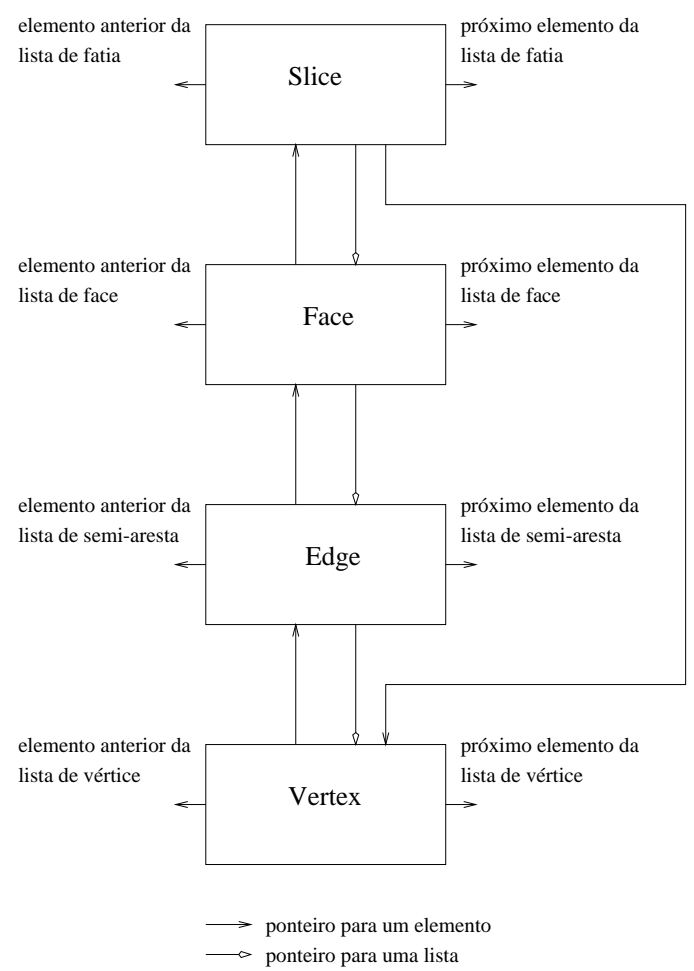

Figura 5.10: Estrutura de dados do FreeFlow 2D

A estrutura de dados deste ambiente oferece um fácil acesso às informações e possui interdependência dos dados de forma a simplificar a manutenção e extensão do código.

Os dados estão divididos da seguinte forma: dados diretos e dados indiretos.

Os dados diretos, por sua vez, estão divididos em:

- Dados estáticos: dados que não são modificados durante a simulação, como as propriedades do fluido: densidade, viscosidade, tensão superficial e interfacial.

Para estes dados existe um vetor estruturado, denominado vphase, onde cada co- 
ordenada armazena as propriedades de cada fase. O tamanho deste vetor estruturado varia de acordo com o número de fases informado pelo usuário, pela janela de entrada de dados ilustrada na figura (5.1). Este número é armazenado num campo deste vetor denominado nphase.

A utilização deste vetor de fases para armazenar as propriedades de cada fluido, possibilita um número arbitrário de fases durante a simulação, sendo limitado apenas pela capacidade de memória de alocação deste vetor.

- Dados dinâmicos: são modificados durante a simulação, como velocidade, pressão, configuração do conjunto de células, e representação dos objetos geométricos.

Dados como velocidade e pressão são representado por matrizes e a configuração do conjunto de células (F, S, E, I e O) é representada por matrizes e árvores.

Para células do tipo interface, também existe uma representação por árvore e matrizes, mesmo não havendo um identificador (label) para esta classe de células. A identificação das células interface decorre seguindo a classificação descrita no seção (4.2) do capítulo 4. A representação por árvore facilita o acesso a uma célula específica. A representação matricial é mais útil no caso de acesso a uma vizinhança de uma determinada célula. Além disso melhora o desempenho de alguns algoritmos do simulador.

A representação por árvore, no caso das células interface se faz necesária, por exemplo, quando se quer determinar as faces destas célula onde serão aplicadas a força intercial, uma vez que estas faces são utilizadas para aproximar a interface.

A representação por matriz é utilizada para armazenar a classificação das células na simulação. Nesta abordagem é usada uma matriz representando a configuração das células de cada fase, como ilustra a figura (5.6) (a) e (b), e uma matriz representando a configuração global das células de todas as fases, figura (5.7), da mesma forma que é usada uma matriz para armazenar cada campo do escoamento multifásico.

Por fim, os dados indiretos são os contêiners, os injetores e ejetores, que formam os componentes da simulação cuja representação segue a estrutura de dados $B$-Rep. No caso de objetos do tipo fluido, cada objeto desta classe terá na estrutura Slice da $B$-Rep, um campo denominado fphase. Este campo armazena o número da fase que este Slice de fluido irá pertencer, possibilitanto o acesso às propriedades de cada fase percorrendo o vetor vphase. 
